\title{
Two methods for controlling three-time fundamental frequency neutral-point voltage oscillation in a hybrid VIENNA rectifier
}

ISSN 1755-4535

Received on 2nd February 2018 Revised 23rd November 2018

Accepted on 15th December 2018 doi: 10.1049/iet-pel.2018.5017 www.ietdl.org

\author{
Wei-zhang Song1,2凶, Zhi-hao Dai', Nan Xie'1, You-yun Wang'2, Wheeler Pat ${ }^{3}$ \\ ${ }^{1}$ School of Automation and Information Engineering, Xi'an University of Technology, Xi'an, Shaanxi, People's Republic of China \\ ${ }^{2}$ State Key Laboratory of Large Electric Drive System and Equipment Technology, Tianshui, Gansu, People's Republic of China \\ ${ }^{3}$ School of Electrical and Electronic Engineering, University of Nottingham, Nottingham, UK \\ 凶E-mail: swz@xaut.edu.cn
}

\begin{abstract}
This study presents two methods of controlling neutral-point voltage oscillation in a hybrid VIENNA rectifier, which is composed of the parallel association of a three-phase single-switch Boost rectifier with a VIENNA-type rectifier. The neutralpoint oscillation reason has been analysed with a mathematical model. Meanwhile, the two neutral-point control methods of a simplified method based on a zero-sequence component injection and a dual-carrier pulse-width modulation (PWM) method are proposed to control the voltage deviation of the split DC-link and three-time fundamental frequency neutral-point voltage fluctuation with a decrease from \pm 1.6 to $\pm 1 \mathrm{~V}$, respectively. Moreover, the significant oscillation in the neutral-point voltage caused by unbalanced loads or asymmetric capacitor parameters can also be effectively suppressed by using the dual-carrier PWM method. Furthermore, the performance comparison between these two methods is provided. The experimental results show that the system after being introduced the proposed two methods still exhibits a low-order input current harmonic such as second, third, and fourth harmonics as well as the input current total harmonic distortion is lower than the standard $5 \%$.
\end{abstract}

\section{Introduction}

The hybrid VIENNA rectifier is assembled by the parallel connection of a three-phase single-switch boost rectifier (TPSSBR) and a VIENNA-type rectifier. The input current of this rectifier is divided into two parts; thus, the input power and current stress on the power switches in each single rectifier can be reduced [1-3]. The hybrid rectifier is reported to have many advantages, including low input current harmonics, higher efficiency, and reliable performance compared with the single rectifier [4-7]. Therefore, this rectifier has an application potential in the aspect of the DC arc furnace, plasma arc torches, electro-winning, plasma cutting system [8,9] and aviation power source [10], and charging pile power source [11], on the other hand, it can also find application in the retrofit projects where a three-phase diode rectifier already exists, but its input current distortion is to be reduced to comply with new standards only through a parallel connection of VIENNA-type switch bridge instead of significant changing the topology structure [9].

The neutral-point voltage oscillation is an inherent problem in three-level topology including hybrid VIENNA rectifier, which can lead to unbalanced voltage of the capacitor and cause the switch over-voltage damage, it also affects the input line voltage waveform as well as making the total harmonic distortion (THD) of input current become large with the same filter parameters [12, 13]. Recently, some suppression methods of neutral-point voltage oscillation have been proposed. Tian et al. [14] took advantage of redundancy in phase switching states to control and balance flying capacitor voltages for a four-level voltage-source inverter. In [15], an improved virtual space vector pulse-width modulation (PWM) with a feedback control scheme is adopted to balance the neutralpoint voltage and to achieve precise control. However, this method relies on a feedback control scheme. A neutral-point voltage balancing control method based on a carrier-based discontinuous PWM for VIENNA rectifier is described in [16], but this neutralpoint control method is not applicable to the continuous PWM system. Song et al. [17] presented a hybrid neutral-point voltage fluctuation control method combining a dynamic adjustment factor with a voltage deviation of two DC-link capacitors in a VIENNA rectifier system. However, the selection of adjusting factors relies on engineering experience and lacks theoretical basis.

The major contribution of this paper is to present two neutralpoint oscillation control methods with a simplified method based on zero-sequence component injection and a dual-carrier PWM method to suppress the voltage deviation of the split DC-link and three-time fundamental frequency neutral-point voltage oscillation in a hybrid-type VIENNA rectifier.

\section{Methodology}

\subsection{Topology analysis of hybrid VIENNA rectifier}

The topology composition of the hybrid VIENNA rectifier is shown in Fig. 1 [18]. The hybrid VIENNA rectifier is a rectifier system connected by a diode rectifier cascade BOOST converter and VIENNA rectifier which is shown in Fig. 2. From Fig. 2, the two rectifiers connected in parallel, respectively, take part of the power of the system. In this way, the current and power stress of the semiconductor switch is reduced [19].

2.1.1 Analysis of neutral-point voltage imbalance: According to the topology structure shown in Fig. 2, the equation of DC-link capacitor voltage and current can be obtained as follows:

$$
\left(\begin{array}{l}
U_{C 1} \\
U_{C 2}
\end{array}\right)=\left(\begin{array}{l}
U_{C 10} \\
U_{C 20}
\end{array}\right)+\left(\begin{array}{l}
\frac{1}{C_{1}} \int_{0}^{t} i_{c 1} \mathrm{~d} t \\
\frac{1}{C_{2}} \int_{0}^{t} i_{c 2} \mathrm{~d} t
\end{array}\right)
$$

$U_{\mathrm{C} 10}$ and $U_{\mathrm{C} 20}$ are the initial voltages of $C_{1}$ and $C_{2}$, respectively.

It can be seen from (1) that the voltage of the capacitor at the DC-link is not only related to the initial value of the capacitor voltage $U_{\mathrm{C} 10}$ and $U_{\mathrm{C} 20}$, but also to the charge-discharge current between the two capacitors. The charge-discharge current that flows through these two capacitors will cause the neutral-point current $i_{\mathrm{o}}$ to contain low-frequency AC oscillation and DC offset, which will cause the voltage deviation of the two capacitors in the DC-link. Based on the analysis of a large number of references 


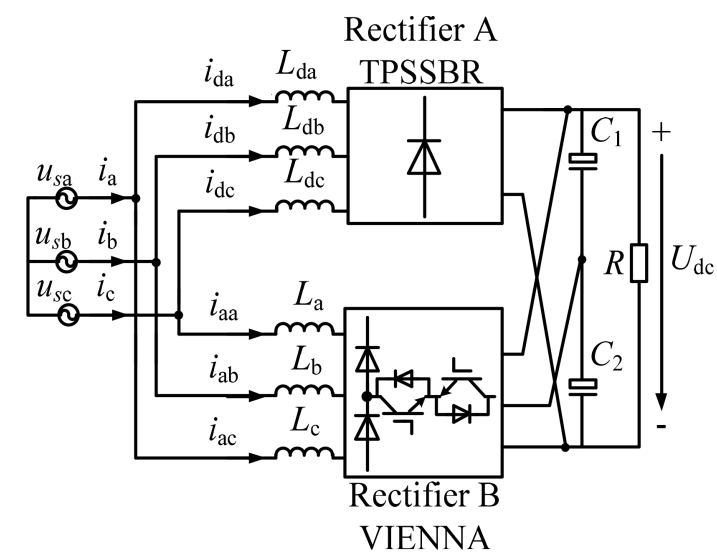

Fig. 1 Topology composition of the hybrid VIENNA rectifier

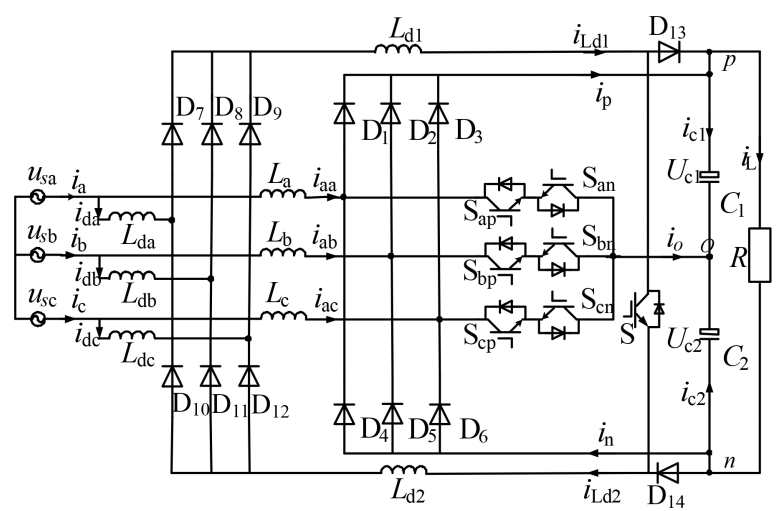

Fig. 2 Topology of the hybrid VIENNA rectifier

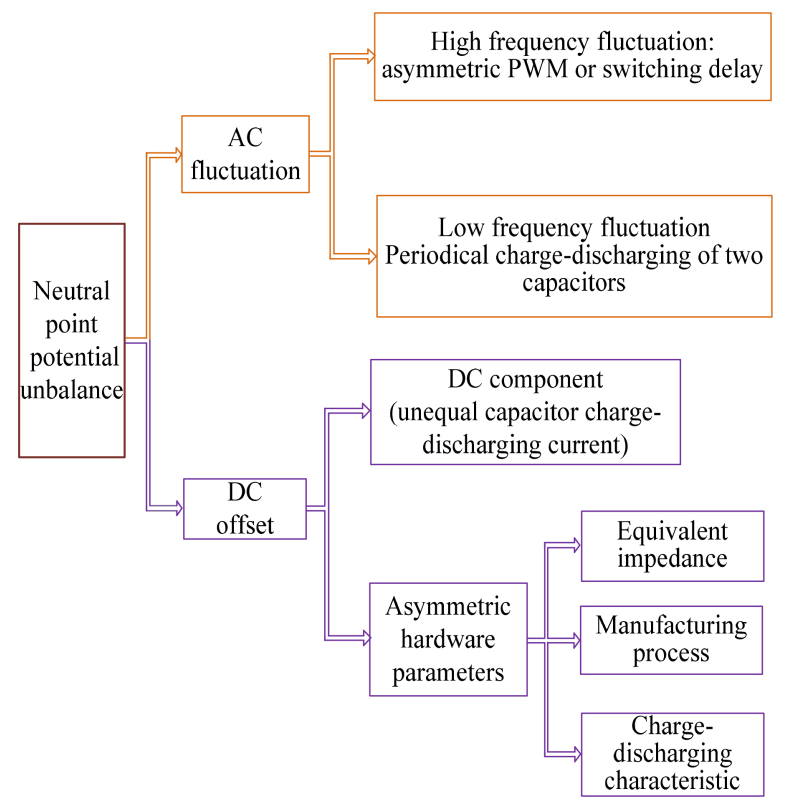

Fig. 3 Forms of neutral-point fluctuation

about the neutral-point fluctuation control of three-level converter, the form and cause of neutral-point voltage unbalance can be summarised as Fig. 3 [20-23].

According to (1) and (2), it is easy to know that the unequal current between the two charge-discharging capacitors in the split DC-link is the reason for the deviation of the two capacitance voltages.

Therefore, it is necessary to analyse the charge-discharging characteristics of two capacitors in the split DC-link by establishing the mathematical model of the neutral-point current $i_{\mathrm{o}}$, so as to find an effective method to solve the voltage unbalance between two capacitors in DC-link of the hybrid VIENNA rectifier.
2.1.2 Neutral-point current mathematical model: According to Fig. 2, the DC-link equation can be obtained as follows:

$$
\begin{gathered}
\left(\begin{array}{c}
i_{p} \\
i_{n}
\end{array}\right)=\left(\begin{array}{c}
1 \\
-1
\end{array}\right) i_{L}+\left(\begin{array}{c}
C_{1} \frac{\mathrm{d} u_{c 1}}{\mathrm{~d} t}-i_{L d 1} \\
C_{2} \frac{\mathrm{d} u_{c 2}}{\mathrm{~d} t}+i_{L d 2}
\end{array}\right) \\
\left\{\begin{array}{l}
i_{\mathrm{o}}=-\left(i_{c 1}+i_{c 2}\right)=C_{2} \frac{\mathrm{d} u_{c 2}}{\mathrm{~d} t}-C_{1} \frac{\mathrm{d} u_{c 1}}{\mathrm{~d} t} \\
i_{\mathrm{o}}=\left(\begin{array}{c}
S_{a} \\
S_{b} \\
S_{c}
\end{array}\right)\left(\begin{array}{l}
i_{a} \\
i_{b} \\
i_{c}
\end{array}\right)
\end{array}\right.
\end{gathered}
$$

$S_{i}$ represents the switching state, and this switching state is defined as follows:

$$
S_{i}= \begin{cases}0 & S_{i} \text { on } . \\ 1 & S_{i} \text { off, } \quad u_{i}>0, \quad i=a, b, c \ldots \\ -1 & S_{i} \text { off, } \quad u_{i}<0 .\end{cases}
$$

To simplify the analysis, the initial voltage of the capacitors is ignored; supposing $u_{c 1}=u_{c 1}(t), u_{c 2}=u_{c 2}(t)$, and by integrating from (3), we have

$$
C_{2} u_{c 2}-C_{1} u_{c 1}=\int_{0}^{t} i_{0} \mathrm{~d} t=\int_{0}^{t}\left[\left(\begin{array}{lll}
S_{a} & & \\
& S_{b} & \\
& & S_{c}
\end{array}\right)\left(\begin{array}{l}
i_{a} \\
i_{a} \\
i_{a}
\end{array}\right)\right]
$$

The value of capacitor $C_{1}$ is equal to capacitor $C_{2}$ in the ideal state; therefore, the neutral-point current expression is shown in the below equation

$$
\left\{\begin{array}{l}
i_{\mathrm{o}}=C\left(\frac{\mathrm{d} u_{c 2}}{\mathrm{~d} t}-\frac{\mathrm{d} u_{c 1}}{\mathrm{~d} t}\right) \\
i_{\mathrm{o}}=\left(i_{a}+i_{b}+i_{c}\right)-\left(\left|u_{a}\right| i_{a}+\left|u_{b}\right| i_{b}+\left|u_{c}\right| i_{c}\right)
\end{array}\right.
$$

where $u_{a}, u_{b}$, and $u_{c}$ are the three-phase modulation signals, which are produced by closed-loop control.

As is shown in Fig. 4, the three-phase modulation signals can be divided into six sectors and each sector is $60^{\circ}$ apart. Taking the sector 4 as an example, the three-phase modulation signals can be written as follows:

$$
u_{a}<0, u_{b}<0, u_{c}>0 .
$$

Substituting (7) into (6), the fundamental frequency neutralpoint expression can be rewritten as follows:

$$
i_{\mathrm{o}}=\left(i_{a}+i_{b}+i_{c}\right)+\left(u_{a} i_{a}+u_{b} i_{b}-u_{c} i_{c}\right)
$$

The sum of three-phase input is zero when the system is symmetric and balanced. Then, the neutral-point current can be rewritten as follows:

$$
i_{\mathrm{o}}=u_{a} i_{a}+u_{b} i_{b}-u_{c} i_{c}
$$

The sum of the three-phase modulation signals is zero in a normal three-phase system, which can be given by

$$
u_{a}+u_{b}+u_{c}=0
$$

The three-phase current instantaneous value can be expressed as (11) when the hybrid rectifier is controlled by a closed-loop control system and with unit power factor

$$
i_{i}=k \cdot u_{i}, \quad i=a, b, c
$$




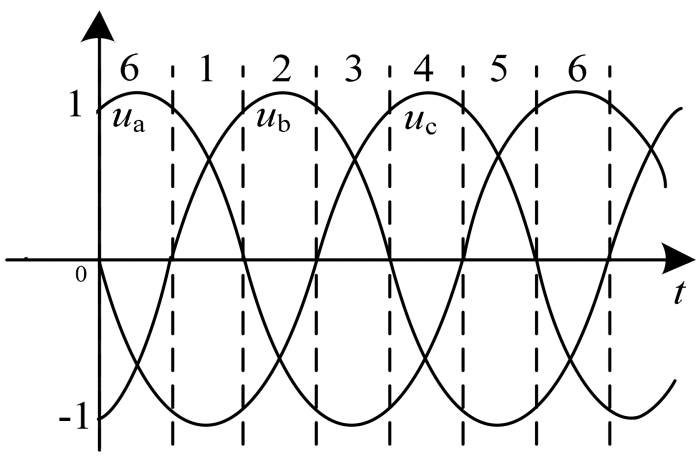

Fig. 4 Sector division of the hybrid VIENNA rectifier

where $k=i_{i} / u_{i}$ is the ratio index between the input current $\left(i_{i}\right)$ and the reference input voltage $\left(u_{i}\right)$, the amplitude $u_{i}$ is a constant positive value obtained from grid voltage. The $i_{i}$ can be expressed as

$$
p_{i}=\sqrt{3} u_{i} i_{i} \cos \varphi_{i} \Rightarrow i_{i}=\frac{p_{i}}{\left(\sqrt{3} u_{i} \cos \varphi_{i}\right)}
$$

where $p_{i}$ is the input active power, and $\cos \varphi_{i}=1$ when a unity power factor is obtained using a closed-loop control.

With (8)-(11), the neutral-point fundamental frequency current can be expressed as follows:

$$
i_{\mathrm{o}}=-2 k u_{b} u_{a}
$$

In sector $4, u_{a}$ and $u_{b}$ have the same polarity. From (13), it is easy to know $i_{\mathrm{o}}<0$, which expresses that the neutral-point current is less than zero in sector 4 with capacitor $C_{1}$ charging and $C_{2}$ discharging. The expressions of neutral-point current $i_{\mathrm{o}}$ in the other five sectors can be calculated in the same way.

The waveform of neutral-point current $i_{\mathrm{O}}$ is drawn according to the above equation as shown in Fig. 5. From the waveform, it can be seen that the neutral-point presents a three-time fundamental frequency oscillation changing with a sinusoidal tendency in real time.

\subsection{Simplified algorithm of neutral-point control based on zero-sequence component injection}

According to Fig. 2, the DC-link capacitance voltage deviation expression can be obtained

$$
\Delta_{u c}=U_{C 1}-U_{C 2}
$$

The three-phase modulation signals compensated by the ac component $v_{\text {ac }}$ can be divided into two parts

$$
d_{i}=u_{i}+v_{\mathrm{ac}}
$$

where $u_{i}$ is the three-phase modulation signal before compensating and $v_{\mathrm{ac}}$ the $\mathrm{AC}$ compensation component.

Substitute (4) into (5), and follow the constraint relation in the equation, the expression of the neutral-point average current in a period can be obtained

$$
i_{\mathrm{o}}=\left(1-\left|u_{a}\right|\right) i_{a}+\left(1-\left|u_{b}\right|\right) i_{b}+\left(1-\left|u_{c}\right|\right) i_{c}
$$

According to (15) and (16), the new neutral-point current expression can be obtained as follows:

$$
i_{\mathrm{o}}=-\left(\left|d_{a}\right| i_{a}+\left|d_{b}\right| i_{b}+\left|d_{c}\right| i_{c}\right)
$$

According to the working principle of the three-phase hybrid VIENNA rectifier, three-phase input voltage and input current should always be in phase. Therefore, the input current and input

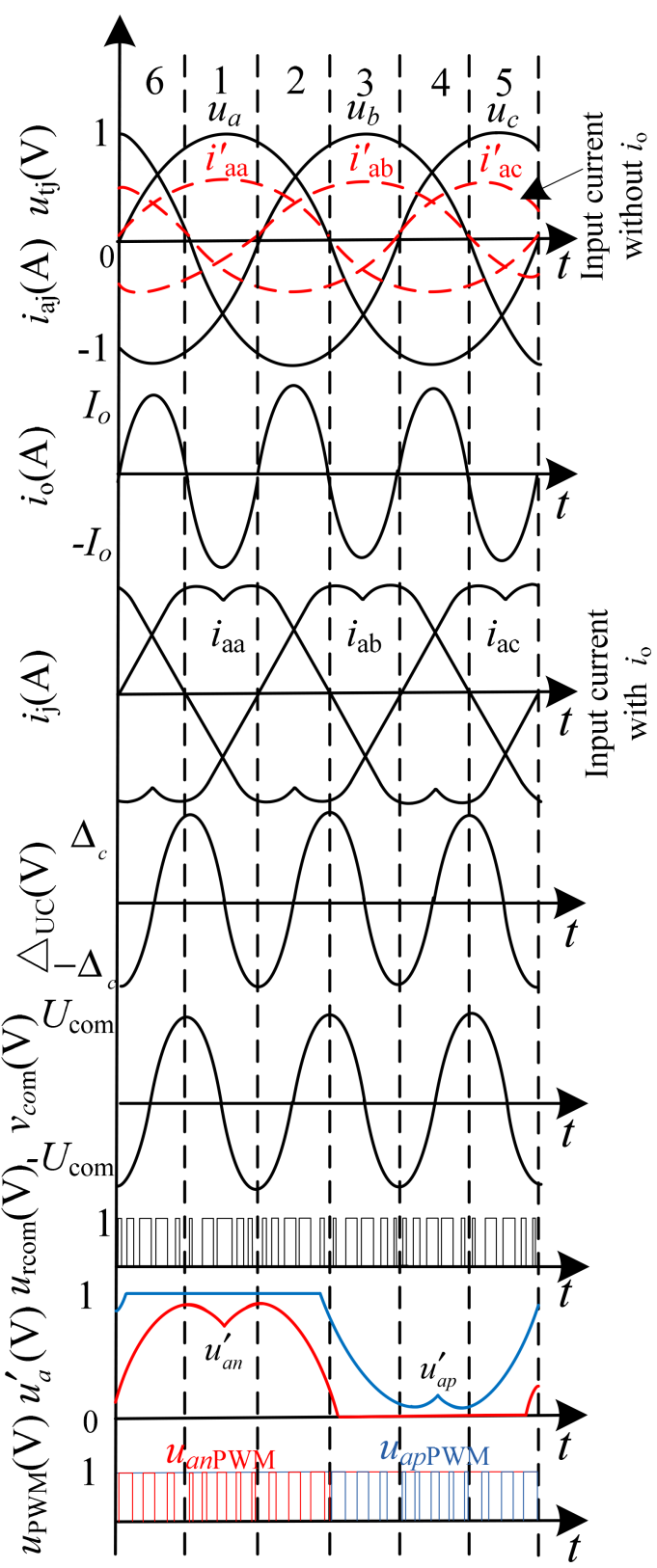

Fig. 5 Ideal waveforms of input current, neutral-point current $i_{O}$, input current with $i_{O}$, capacitor voltage deviation, zero-sequence components modulation signal of phase $a$, and dual carrier with the corresponding PWM wave

voltage are of the same polarity. If $d_{\mathrm{i}} \geq 0, i_{\mathrm{i}} \geq 0$. If $d_{\mathrm{i}}<0, i_{i}<0$. $\left|d_{i}\right|$ and $i_{i}$ can be expressed as follows:

$$
\left|d_{i}\right|=d_{i}\left(\operatorname{sign}\left(i_{i}\right)-\operatorname{sign}\left(-i_{i}\right)\right)
$$

The symbolic function shown in (18) is defined as follows:

$$
\operatorname{sign}(x)= \begin{cases}1 & x \geq 0 \\ 0 & x<0\end{cases}
$$

From (17) and (18), the expression of the neutral-point average current $i_{\mathrm{o}}$ can be written as

$$
\begin{aligned}
-i_{\mathrm{o}}= & d_{a}\left(\operatorname{sign}\left(i_{a}\right)-\operatorname{sign}\left(-i_{a}\right)\right) i_{a} \\
& +d_{b}\left(\operatorname{sign}\left(i_{b}\right)-\operatorname{sign}\left(-i_{b}\right)\right) i_{b} \\
& +d_{c}\left(\operatorname{sign}\left(i_{c}\right)-\operatorname{sign}\left(-i_{c}\right)\right) i_{c}
\end{aligned}
$$

The absolute value of the input current can be expressed as 


$$
\left|i_{i}\right|=i_{i}\left(\operatorname{sign}\left(i_{i}\right)-\operatorname{sign}\left(-i_{i}\right)\right)
$$

Then from (17), (20), and (21), $i_{0}$ can be written as

$$
i_{\mathrm{o}}=-\left(d_{a}\left|i_{a}\right|+d_{b}\left|i_{b}\right|+d_{c}\left|i_{c}\right|\right)
$$

In order to remove the voltage deviation of DC-link two capacitors, the neutral-point current $i_{\mathrm{o}}$ must be equal to zero in each sector as well as can be written as

$$
i_{\mathrm{o}}=0
$$

Therefore, from (15), (22), and (23), the AC compensation component of the neutral-point fluctuation can be obtained by

$$
v_{\mathrm{ac}}=-\frac{u_{a}\left|i_{a}\right|+u_{b}\left|i_{b}\right|+u_{c}\left|i_{c}\right|}{\left|i_{a}\right|+\left|i_{b}\right|+\left|i_{c}\right|}
$$

In order to remove the DC-link capacitor voltage deviation effectively, the DC compensation component formed by DC-link two capacitors voltage deviation is added to this compensation expression. In this way, the compensation expression $\left(V_{\text {com }}\right)$ based on zero-sequence component injection formed by $\mathrm{AC}$ and $\mathrm{DC}$ compensation components can be written as

$$
V_{\text {com }}=v_{\mathrm{ac}}+\Delta_{u c}
$$

A closed-loop control block diagram of the hybrid VIENNA rectifier based on the above simplified neutral-point voltage balance control is shown in Fig. 6. The zero-sequence component injection compensation expression $\left(V_{\text {com }}\right)$ is composed of an $\mathrm{AC}$ compensation component $v_{\mathrm{ac}}$ and a DC compensation component $\Delta_{u c}$. The three-phase reference voltage signals compensated by these zero-sequence components are used as new modulated signals to realise neutral-point voltage balance control of the hybrid VIENNA rectifier system.

\subsection{Neutral-point balance control based on dual-carrier PWM method}

The modulation waves $u_{a}, u_{b}$, and $u_{c}$ can be expressed as

$$
\left\{\begin{array}{l}
u_{a}=m \cos (\omega t) \\
u_{b}=m \cos (\omega t-2 \pi / 3) \\
u_{c}=m \cos (\omega t+2 \pi / 3)
\end{array}\right.
$$

where $m$ is the modulation coefficient, and $0<m \leq 1$. When the zero-sequence component is injected, the value of $m$ can be $>1$.

From [24], the phase pulse-width duty cycle is defined as the ratio of the positive or negative phase voltage pulse width in the carrier period. The phase pulse-width duty cycle $d_{x}$ can also be defined as the ratio of the modulation wave instantaneous value $(-1-1)$ to the corresponding carrier amplitude $(1$ or -1$)$. It can be expressed as: $d_{x}=\left|u_{x}\right|$. Therefore, in the dual-carrier modulation, the same principle can be used to define the positive state duty cycle $d_{x p}$ as the ratio of the positive modulation wave $u_{x p}$ to the corresponding positive carrier amplitude, which can be expressed as $d_{x p}=u_{x p}$. The negative-state duty cycle $d_{x n}$ is the absolute value of the ratio of the negative modulated wave $u_{x n}$ to the corresponding load wave amplitude, which can be expressed as: $d_{x n}=\left|u_{x n}\right|$. The zero-state (connecting to o) duty cycle $d_{x \mathrm{o}}(x=a$, $b, c)$ can be defined as the ratio of zero-state duration in a carrier period to the whole period, and all the duty cycles should satisfy the constraint: $d_{x p}+d_{x n}+d_{x \mathrm{o}}=1$.

In general, the phase modulation wave consists of positive modulation wave $u_{x p}$ and negative modulation wave $u_{x n}$, which can be written as

$$
\left|u_{x}\right|=\left|u_{x p}\right|+\left|u_{x n}\right|
$$

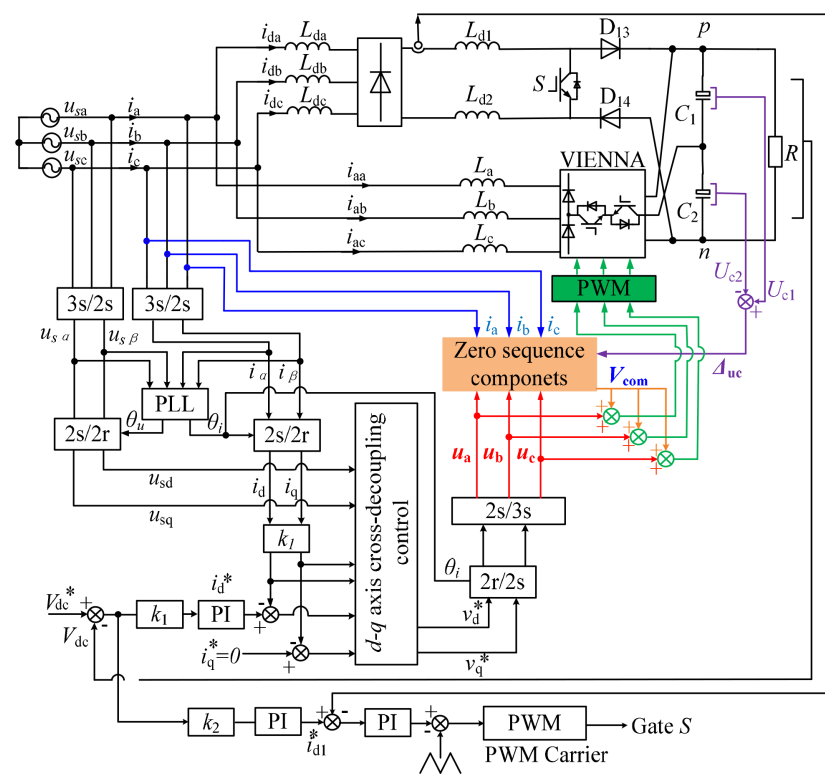

Fig. 6 Control system block diagram of $d$-q-axis cross-decoupling control based on the simplified neutral-point control method

Therefore, the relationship between the zero-state duty cycle $d_{x \mathrm{o}}$ and the $x$-phase modulation wave $u_{x}(x=a, b, c)$ is as follows:

$$
d_{x \mathrm{o}}=1-\left|u_{x}\right|
$$

From (16) and (28), the neutral-point current $i_{0}$ can be written as

$$
i_{\mathrm{o}}=d_{a \mathrm{o}} i_{a}+d_{b \mathrm{o}} i_{b}+d_{c \mathrm{o}} i_{c}
$$

The neutral-point average current $i_{\mathrm{o}}$ should be controlled to be zero all the time, so that the oscillation of the neutral-point voltage can be suppressed under any circumstances. In a control cycle, the expression of the neutral-point current $i_{\mathrm{o}}$ is shown in (29). For a three-phase three-wire system, the sum of the three-phase input currents is zero when the system is balanced, namely $i_{a}+i_{b}+i_{c}=0$. If the zero-state duty cycle of each phase is the same, that is, $d_{a 0}=$ $d_{b o}=d_{c 0}$, the neutral-point average current can also remain zero.

For any modulation strategy, phase current should be always function as its corresponding original modulation signal, otherwise the input current would be distorted. The hybrid VIENNA rectifier input voltage is exactly the same as the current waveform, so the original modulated wave needs to be consistent with the input voltage. The average voltage of any phase during a carrier cycle is $d_{x p}-d_{x n}$. Then, the equation of the modulation voltage signal between phase $a$ and phase $b$, phase $b$ and phase $c$ can be expressed as

$$
\left\{\begin{array}{l}
\left(d_{a p}-d_{a n}\right)-\left(d_{b p}-d_{b n}\right) \\
=\left(u_{a p}-\left(-u_{a n}\right)\right)-\left(u_{b p}-\left(-u_{b n}\right)\right) \\
=u_{a}-u_{b} \\
\left(d_{b p}-d_{b n}\right)-\left(d_{c p}-d_{c n}\right) \\
=\left(u_{b p}-\left(-u_{b n}\right)\right)-\left(u_{c p}-\left(-u_{c n}\right)\right) \\
=u_{b}-u_{c}
\end{array}\right.
$$

The aim is to make the zero-state duty cycles of the three phases completely equal, which means $d_{\mathrm{o}}=d_{a \mathrm{o}}=d_{b \mathrm{o}}=d_{c 0}$, and to satisfy the constraint equation shown in (30).

If the method of double modulation waves is used, there will be three states for each phase to output in one carrier cycle, and then the positive duty cycle and the negative duty cycle can be flexibly distributed. The expression of the negative duty cycle is written as: $d_{a n}=1-d_{a p}-d_{\mathrm{o}}, d_{b n}=1-d_{b p}-d_{\mathrm{o}}$ and $d_{c n}=1-d_{c p}-d_{\mathrm{o}}$. Substituting them into (30), one can get the following expression 


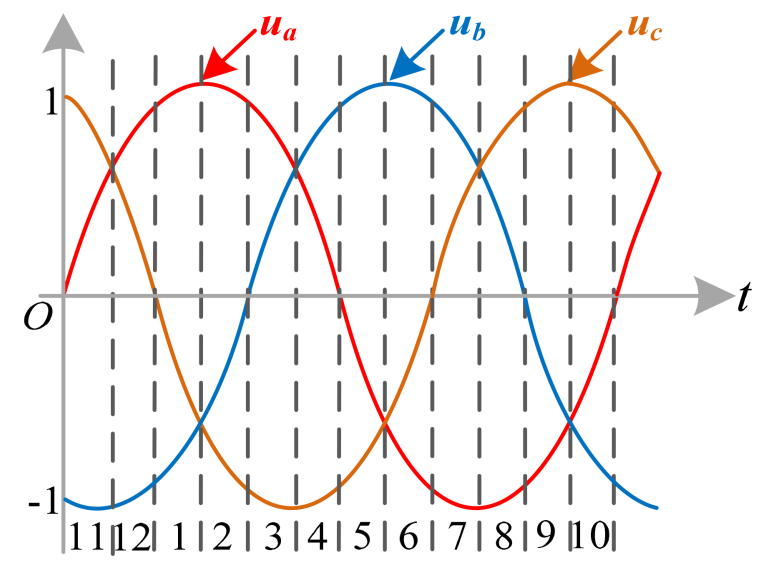

Fig. 7 Schematic diagram of the sector division

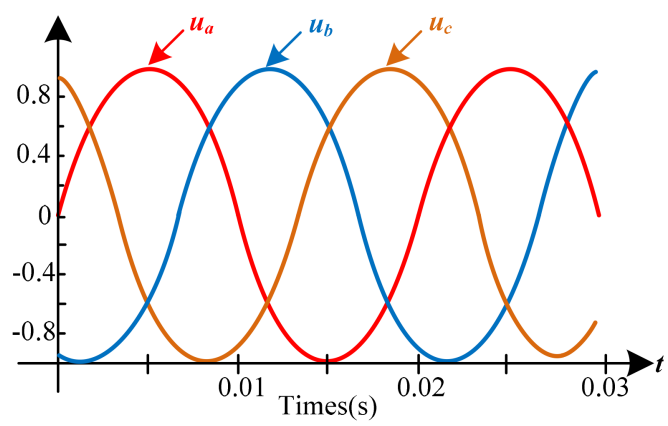

a

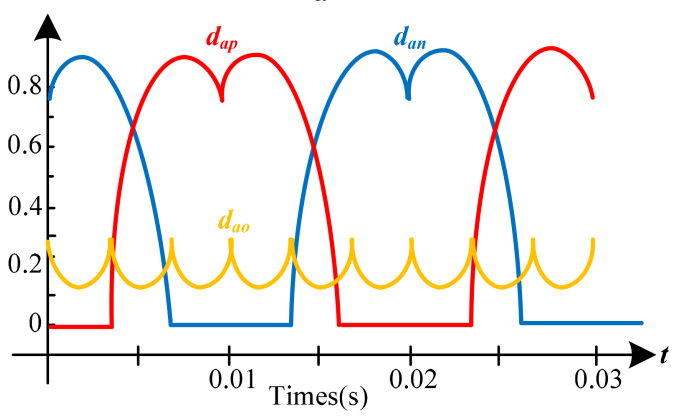

$b$

Fig. 8 Waveforms of modulation and duty cycles $(m=1)$

(a) Original modulation waveforms, $m=1$, (b) Positive, negative, and zero-state duty cycles of phase $a$ in the proposed method

$$
\left\{\begin{array}{l}
2 d_{a p}-2 d_{b p}=u_{a}-u_{b} \\
2 d_{b p}-2 d_{c p}=u_{b}-u_{c}
\end{array}\right.
$$

It can be solved by the above equation

$$
\left\{\begin{array}{l}
d_{a p}=u_{a} / 2+d_{\mathrm{off}} \\
d_{b p}=u_{b} / 2+d_{\mathrm{off}} \\
d_{c p}=u_{c} / 2+d_{\mathrm{off}}
\end{array}\right.
$$

where $d_{\text {off }}$ represents the offset. Table 1 shows the positive duty cycle, negative duty cycle, and zero-state duty cycle expressions for each phase.

In these expressions, the values of $d_{\text {off }}$ and $d_{\mathrm{o}}$ are unknown, so the next step is to get them. There are many ways to solve the above problems. This paper chooses to solve the problem with reducing switching loss as the optimisation goal.

Assuming that the output has two states in one carrier cycle, such as non or npn, then the two switches will be turned on and off, and the switching action is 4 . If the output has three states, then the number of switches will become 8 . Therefore, in one carrier cycle, one of the positive or negative duty cycles is preferably zero, and there are only two states for a phase output, so that the switching losses can be reduced.
Table 1 Duty cycles of each phase in a carrier period

\begin{tabular}{lccc}
\hline Phase & $d_{x p}$ & $d_{x n}$ & $d_{x o}$ \\
\hline$a$ & $u_{a} / 2+d_{\text {off }}$ & $1-d_{0}-u_{a} / 2-d_{\text {off }}$ & $d_{0}$ \\
$b$ & $u_{b} / 2+d_{\text {off }}$ & $1-d_{0}-u_{b} / 2-d_{\text {off }}$ & $d_{0}$ \\
$c$ & $u_{c} / 2+d_{\text {off }}$ & $1-d_{0}-u_{c} / 2-d_{\text {off }}$ & $d_{0}$ \\
\hline
\end{tabular}

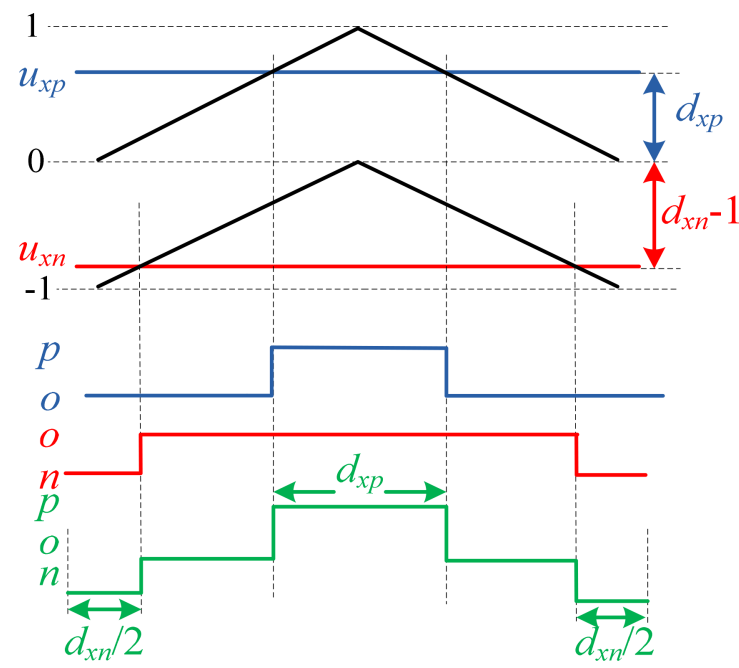

Fig. 9 Generation process for the modulation waveforms

The three-phase modulation waves are divided into 12 sectors, each interval is $30^{\circ}$, which is shown in Fig. 7.

In sector $1, u_{a}>0, u_{b}<0, u_{c} \leq 0$, and $u_{b}$ is the minimum, in this case, the minimum value of the three-phase positive state duty cycle $d_{x p}$ is $d_{b p}=u_{b} / 2+d_{\text {off. }}$. If one sets $d_{b p}$ as zero, the offset value is $d_{\text {off }}=\left|u_{b}\right| / 2$. The minimum of $d_{x n}$ is $d_{a n}=1-d_{0}-u_{a} / 2-d_{\text {off. If }}$ $d_{a n}$ is set to be zero, the zero duty cycle is $d_{\mathrm{o}}=1-u_{a} / 2-d_{\mathrm{off}}=1-$ $u_{a} / 2-\left|u_{b}\right| / 2$.

In sector $4, u_{a} \geq 0, u_{b} \geq 0, u_{c}<0$, and $u_{a}$ is the maximum. In this case, the minimum value of the three-phase positive state duty

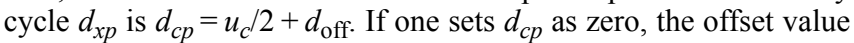
is $d_{\text {off }}=\left|u_{c}\right| / 2$. The minimum of $d_{x n}$ is $d_{a n}=1-d_{\mathrm{o}}-u_{a} / 2-d_{\text {off. If }}$ $d_{a n}$ is set to be zero, the zero duty cycle is $d_{\mathrm{o}}=1-u_{a} / 2-d_{\mathrm{off}}=1-$ $u_{a} / 2-\left|u_{c}\right| / 2$.

The situation for other sectors is similar. Therefore, the offset value $d_{\text {off }}$ and zero-state duty cycle $d_{\mathrm{o}}$ can be summarised as the following expression

$$
\left\{\begin{array}{l}
d_{\mathrm{off}}=\left|u_{\min }\right| / 2 \\
d_{\mathrm{o}}=1-u_{\max } / 2-\left|u_{\min }\right| / 2
\end{array}\right.
$$

where $u_{\min }=\min \left\{u_{a}, u_{b}, u_{c}\right\}$, and $u_{\max }=\max \left\{u_{a}, u_{b}, u_{c}\right\}$. Since $u_{a}$ $+u_{b}+u_{c}=0$, it is obvious that $u_{\min }<0$ and $u_{\max }>0$, then (33) can be rewritten as

$$
\left\{\begin{array}{l}
d_{\mathrm{off}}=-u_{\min } / 2 \\
d_{\mathrm{o}}=1-u_{\max } / 2+u_{\min } / 2
\end{array}\right.
$$

When the modulation coefficient $m$ is equal to 1 , the original threephase modulation waves and the duty cycles of the $a$-phase proposed herein are shown in Fig. 8.

Now the optimal solutions to $d x p, d x n$, and $d o$ have been obtained, and the next step is to generate the modulation waveforms. Each phase has two kinds of modulation waves: $u_{x p}$ and $u_{x n}(x=a, b, c)$. Corresponding to it, $u_{x p}$ is a positive modulated wave, which can produce two states $-p$ and $o$, and $u_{x n}$ is a negative modulated wave, which can produce the states of $n$ and $o$. The modulation wave generation process is shown in Fig. 9.

As is shown in Fig. 9, the blue line indicates the state of the output of the modulation signal $u_{x p}$, and the red line indicates the 


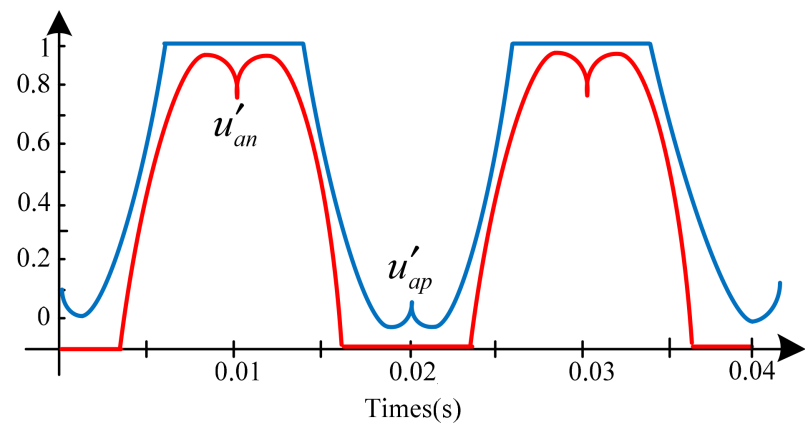

Fig. 10 Positive and negative modulation waveforms of phase a when its switching sequence is rearranged reversely

Table 2 Duty cycle of each phase with voltage balance control

\begin{tabular}{lccc}
\hline Phase & $d_{x p}$ & $d_{x n}$ & $d_{\mathrm{o}}$ \\
\hline$a$ & $u_{a} / 2+d_{\text {off }}-\Delta d_{\mathrm{o}} / 2$ & $1-\Delta d_{\mathrm{o}}-u_{\mathrm{a}} / 2-d_{\mathrm{off}}-\Delta d_{\mathrm{o}} / 2$ & $d_{\mathrm{o}}+\Delta d_{\mathrm{o}}$ \\
$b$ & $u_{b} / 2+d_{\mathrm{off}}$ & $1-\Delta d_{\mathrm{o}}-u_{\mathrm{b}} / 2-d_{\mathrm{off}}$ & $d_{\mathrm{o}}$ \\
$c$ & $u_{\mathrm{c}} / 2+d_{\text {off }}-\Delta d_{\mathrm{o}} / 2$ & $1-\Delta d_{\mathrm{o}}-u_{\mathrm{c}} / 2-d_{\text {off }}-\Delta d_{\mathrm{o}} / 2$ & $d_{\mathrm{o}}-\Delta d_{\mathrm{o}}$ \\
\hline
\end{tabular}

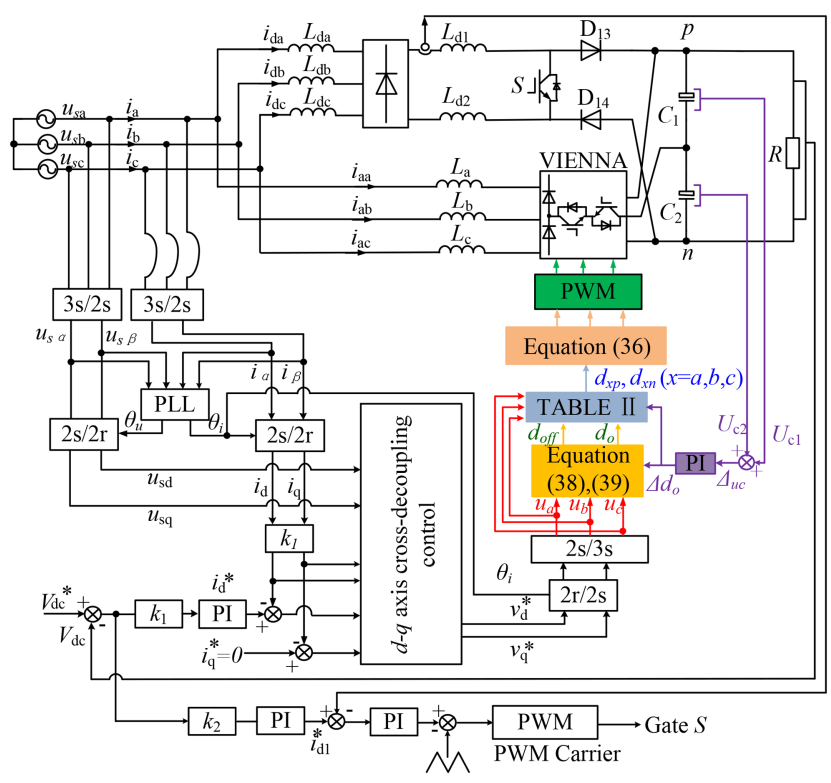

Fig. 11 Control system block diagram of $d$-q-axis cross-decoupling control based on the proposed dual-carrier PWM method with neutralpoint voltage balance control

output state of $u_{x n}$. The green line indicates the combination of the two output states, which is reversely reordered and the duty cycles are consistent with the previous states. When $u_{x}>0$, the switch is turned on while the carrier wave is larger than the modulation wave, the positive state duty cycle is $d_{x p}$, and $u_{x p}=d_{x p}$ at this time; when $u_{x}<0$, the switch is turned on while the carrier wave is smaller than the modulation wave, and the negative-state duty cycle is $d_{x n}$. So, the dual modulation waveforms $u_{x p}$ and $u_{x n}$ can be expressed as

$$
\left\{\begin{array}{l}
u_{x p}=d_{x p} \\
u_{x n}=d_{x n}-1
\end{array}\right.
$$

In order to facilitate the implementation of simulation and experiment, the carrier with positive amplitude in dual carrier is reserved, and the negative carrier wave is inverted. Then, the double modulation waveforms $u_{x p}^{\prime}$ and $u_{x n}^{\prime}$ for the phase with reversed switching sequence can be expressed as

$$
\left\{\begin{array}{l}
u_{x p}^{\prime}=d_{x p} \\
u_{x n}^{\prime}=1-d_{x n}
\end{array}\right.
$$

If phase $a$ is chosen to reverse its switching sequence, according to the duty cycles of phase $a$ in Fig. $8 b$, the positive and negative modulation waveforms of phase $a$ can be drawn in Fig. 10.

In order to recover from the DC-link capacitor voltage imbalance, the phase duty cycles could be modified to control the neutral-point current to charge or discharge the DC-link capacitors. For example, if $i_{a}$ is the maximum and $i_{c}$ is the minimum of the output currents, it is obvious that $i_{a}>0, i_{c}<0$. The modified neutralpoint current can be expressed as

$$
\begin{aligned}
i_{\mathrm{o}} & =d_{a \mathrm{o}} i_{a}+d_{b \mathrm{o}} i_{b}+d_{c \mathrm{o}} i_{c} \\
& =\left(d_{\mathrm{o}}+\Delta d_{\mathrm{o}}\right) i_{a}+d_{\mathrm{o}} i_{b}+\left(d_{\mathrm{o}}-\Delta d_{\mathrm{o}}\right) i_{c} \\
& =\Delta d_{\mathrm{o}}\left(i_{a}-i_{c}\right)
\end{aligned}
$$

where $\Delta d_{\mathrm{o}}$ is the modified zero-state duty cycle. If the DC-link capacitor voltage $U_{c 1}$ is lower than $U_{c 2}$, the modified zero-state duty cycle $\Delta d_{0}$ is set to be positive. So, the neutral-point current is charged by $C_{1}$ and discharged by $C_{2}$, and vice versa. If the zerostate duty cycle of one phase has been modified, the positive and negative-state duty cycles should also be modified to satisfy the constraint equation $d_{x p}+d_{x n}+d_{x \mathrm{o}}=1$. With neutral-point voltage balance control, the duty cycles of each phase are listed in Table 2 .

Assuming $u_{\min \_d}$ and $u_{\max \_d}$ are

$$
\left\{\begin{array}{l}
u_{\text {min_d } d}=\min \left\{u_{a}-\Delta d_{0}, u_{b}, u_{c}+\Delta d_{0}\right\} \\
u_{\text {max } \_d}=\max \left\{u_{a}+\Delta d_{0}, u_{b}, u_{c}-\Delta d_{0}\right\}
\end{array}\right.
$$

Since the sum of all the elements in the bracket is zero, it is obvious that $u_{\min \_}<0$ and $u_{\text {max } \_} d>0$. The minimum of $d x p(x=a$, $b, c)$ is $u_{\text {min } d} d 2+d_{\text {off }}$, and the minimum of $d x n(x=a, b, c)$ is $1-$ $u_{\text {max }} d / 2-\bar{d}_{\mathrm{o}}-d_{\text {off. }}$ The optimisation objective is still to make the switching numbers minimum in one carrier period; thus, the offset value $d_{\text {off }}$ and zero-state duty cycle $d_{\mathrm{o}}$ can be derived as

$$
\left\{\begin{array}{l}
d_{\text {off }}=-u_{\text {min_d} d} / 2 \\
d_{0}=1-u_{\text {max } \_d} / 2+u_{\text {min_ } \_d} / 2
\end{array}\right.
$$

The schematic of the proposed double modulation method with neutral-point voltage balance control is shown in Fig. 11, and a proportional-integral (PI) controller is used to obtain the modified zero-state duty cycle $\Delta d_{0}$.

Under the proposed modulation strategy, the neutral-point current $i_{\mathrm{o}}$ could be kept to zero, so the low-frequency voltage oscillation on the neutral point is eliminated.

\subsection{Improvement mechanism of input current THD by neutral-point control method}

The equivalent circuit of a single-phase VIENNA rectifier is shown in Fig. 12. According to Fig. 12 and Kirchhoff's current law, it is easy to know that the neutral-point current $i_{\mathrm{o}}$ is a part of input current $i_{a a}$ in the equivalent circuit of phase $a$. Thus, the neutralpoint current would make an impact on the input current performance.

As analysed in Section 2.1.2, the waveform of the ideal neutralpoint current $i_{\mathrm{o}}$ can be drawn as shown in Fig. 5. As can be seen in Fig. 5, the neutral-point current $i_{\mathrm{o}}$ expresses a three-time fundamental frequency fluctuation. According to the aforementioned relationship between the input current $i_{a a}$ (input current of phase $a$ ) and $i_{o}$, the input current $i_{a j}$ presents a saddlewave including three-time fundamental frequency $i_{\mathrm{o}}$ as shown in Fig. 5 when neutral-point fluctuation is not controlled. Furthermore, according to the characteristics of capacitance, the neutral-point current lags the voltage deviation of DC-link two capacitors by $90^{\circ}$, and the neutral-point voltage deviation can be 


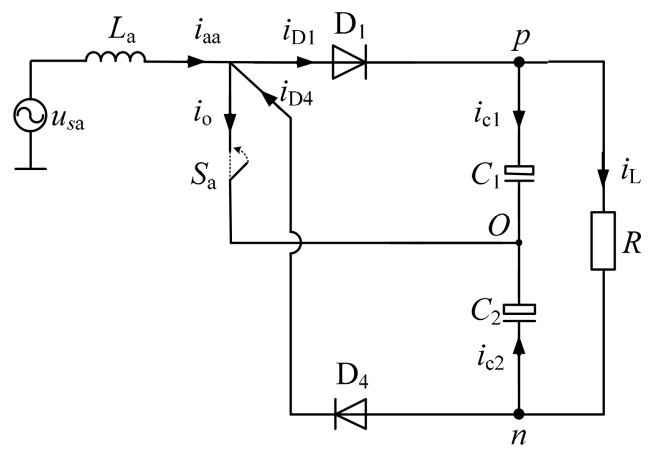

Fig. 12 Equivalent circuit of phase a for the VIENNA rectifier
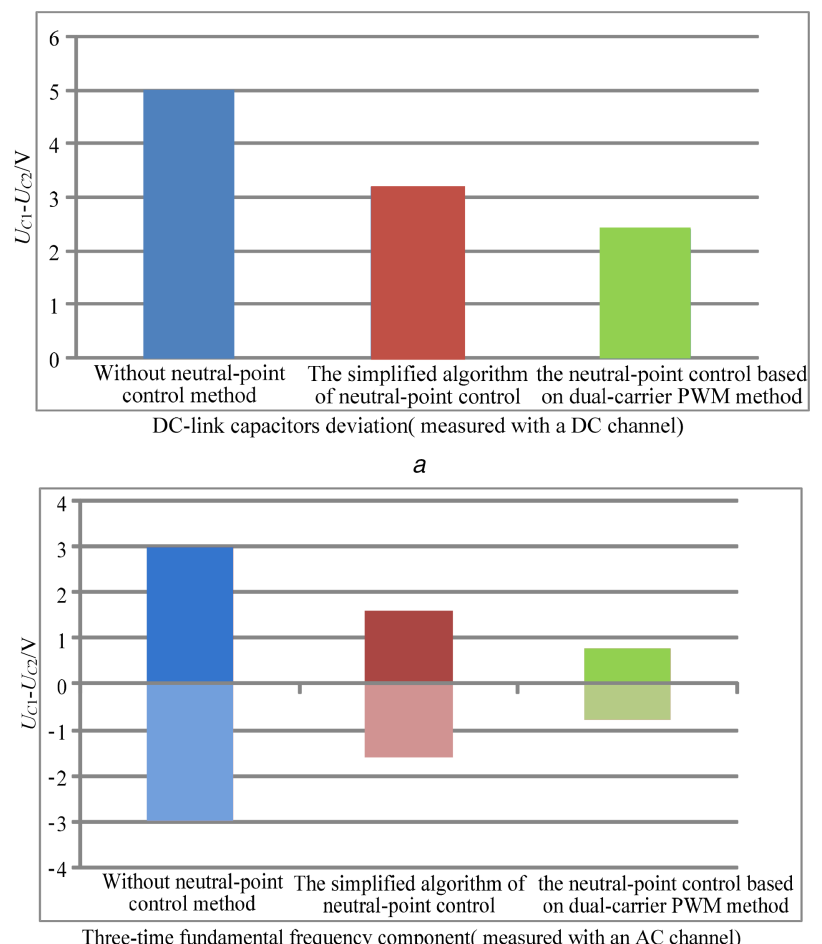

$b$

Fig. 13 DC-link capacitors voltage deviation measured with (a) A DC channel, (b) An AC channel under the no neutral-point control method, the simplified algorithm of neutral-point control method, and the neutral-point control based on dual-carrier PWM method

obtained as shown in the fourth waveform in Fig. 5. According to (25), the waveform of zero-sequence components $V_{\text {com }}$ as well as its corresponding PWM can be drawn as the fifth and sixth waves of Fig. 5. As is shown in Fig. 5, the pulse width of $u_{\text {rcom }}$ is inversely proportional to the magnitude of $u_{\text {com; }}$ thus, the fluctuation of capacitor voltage deviation and neutral-point current can all be compensated by using this PWM, and thereby, the lowfrequency harmonic of input current is reduced by the aforementioned neutral-point compensated method. According to the modulation waveforms shown in Fig. 5 and the modulation strategy applied in the closed loop, it is easy to obtain the PWM signals as shown in the last picture of Fig. 5. As can be seen from the PWM waveforms, since the waveform of the modulation wave is changed, which is sunken at the peak to form a saddle-shaped wave, so that the pulse-width of the PWM wave at the modulation peak is reversely changed, and this change compensates for the low-frequency harmonics of the input current caused by the neutral-point potential fluctuations.

\subsection{Comparison between the two neutral-point control methods}

In this section, a comparison of two neutral-point control methods between the simplified algorithm based on zero-sequence component injection and the dual-carrier PWM algorithm will be carried out.

In order to compare the control performance of the two control methods more clearly, in this section, the suppression effect of the neutral-point current, the suppression effect of three-time fundamental frequency neutral-point voltage oscillation, the THD of input current, the voltage deviation of DC-link capacitors, and the computing time of the two algorithms in controller will be taken into account.

It can be seen from Section 2.2 that the simplified algorithm of neutral-point control method mainly suppresses the neutral-point current by the compensated component $\left(V_{\text {com }}\right)$ calculated by (24) and (25). However, the DC-link capacitance voltage deviation takes up a large weight in the compensation component $\left(V_{\text {com }}\right)$, which makes the ability to suppress capacitance voltage deviation instead of neutral-point current. It also can be seen from Section 2.3 that the neutral-point control based on dual-carrier PWM method makes the three-phase zero-state duty cycle $d_{a 0}=d_{b 0}=d_{c o}$ $=d_{\mathrm{o}}$ always satisfied in any time. According to the neutral-point expression $i_{\mathrm{o}}=d_{a \mathrm{o}} i_{a}+d_{b o} i_{b}+d_{c o} i_{c}$, it is easy to know that the neutral-point current $i_{\mathrm{o}}$ can always remain zero. Therefore, the second method has a better effect on suppressing the neutral-point current. Three-time fundamental frequency current is the main component of the neutral-point current $i_{\mathrm{o}}$. From the above analysis, the neutral-point control method based on dual-carrier PWM method has a better suppression effect on the neutral-point current. Therefore, it is obvious that this method has a better effect on suppressing the three-time fundamental frequency fluctuation of the neutral-point current. More specifically, seen from in Fig. 5, the compensated signal $u_{a}^{\prime}$ obtained from the dual-carrier PWM method is a saddle-wave including the three-time fundamental frequency component, the pulse width $u_{a}{ }^{\prime}$ is inversely proportional to the magnitude of compensated signal, thus, the second method has a better effect on suppressing the three-time fundamental frequency fluctuation of neutral-point current, which is also reflected in Figs. 13 or 14. As described in Section 2.4, the midpoint current of the low-frequency oscillation is the primary source of low-order harmonics in the input current, while the lowfrequency harmonic components directly affect the THD of the input current. According to the above analysis and the conclusion at the end of Section 2.4, the second method has a better suppression effect on the low-frequency fluctuation of the neutralpoint current, and has a lower THD of input current compared with the first method. In the process of controlling the capacitance voltage deviation, although the component $\left(V_{\text {com }}\right)$ in the first method contains the DC compensation component, the weight is fixed. The second method compensates the modulated wave by using $\Delta d_{\mathrm{o}}=\left(k_{\mathrm{p}}+\left(k_{\mathrm{i}} / S\right)\right) \Delta_{u c}$, and the adopted PI controller makes the voltage deviation of the DC-link capacitors always tend to zero. Accordingly, the second method has a better suppression effect on the voltage deviation of the DC-link capacitor. About the CPU processing time of the two algorithms, the first method compensates the modulated wave by calculating the zero-sequence component using (14)-(25). The component $\left(V_{\text {com }}\right)$ is complicated to calculate and its $\mathrm{CPU}$ operating time is long. The second method, through the combination of table lookup (Table 2) and calculation, only performs simple calculations [(26), (38), and (39)] in each control cycle, the complexity of the second method is greatly reduced, and the operating time is short. Seen from the experimental test waveforms of the operating time of the two methods for the code through a GPIO output of controller as shown in Fig. 15, the operating time of the second neutral-point control methods just costs $7.5 \mu \mathrm{s}$, which is significantly shorter than the operating time of the first method. The performance comparison of neutral-point balance control between the two proposed control methods is shown in Table 3 .

\subsection{Loss comparison analysis between the hybrid VIENNA rectifier and VIENNA rectifier}

The hybrid VIENNA rectifier is composed of the parallel association of a TPSSBR and a VIENNA rectifier, each rectifier in 


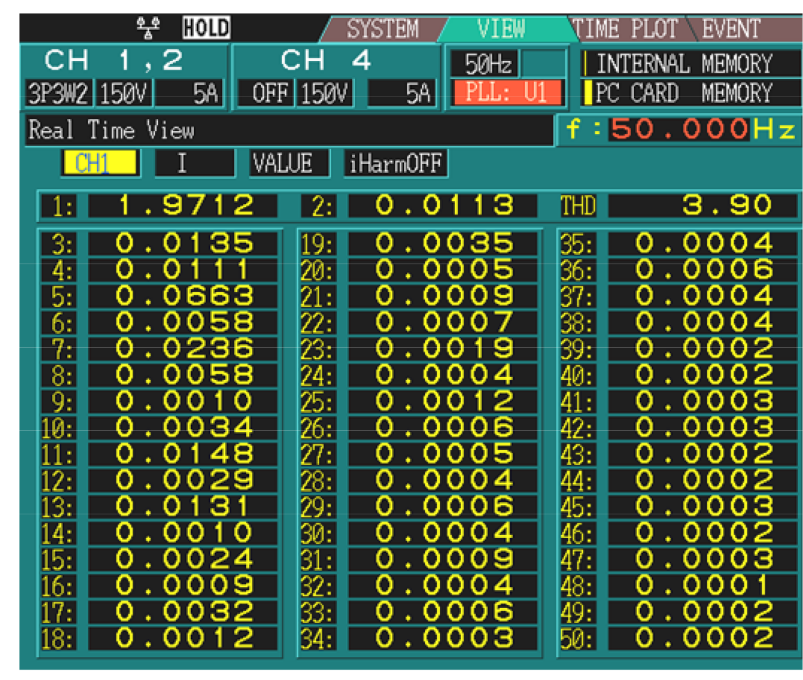

a

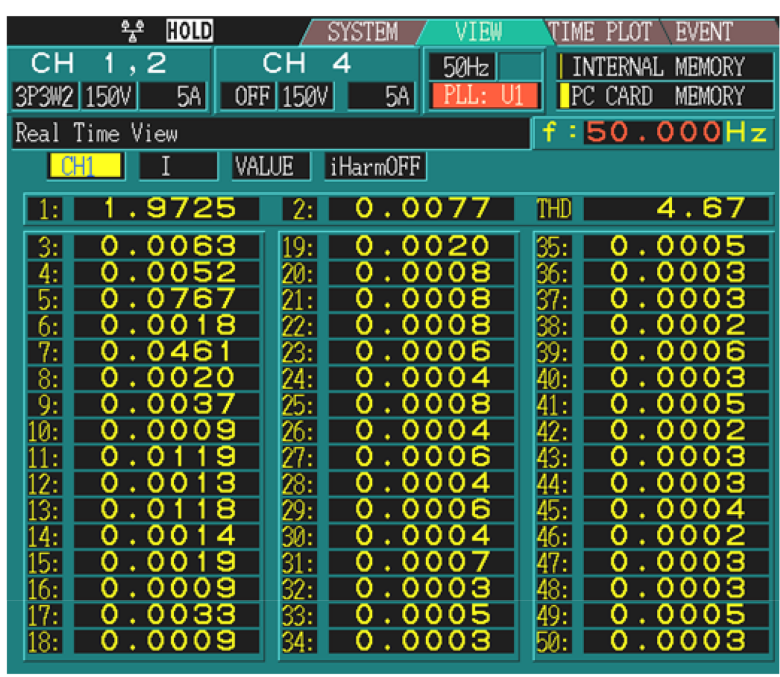

$b$

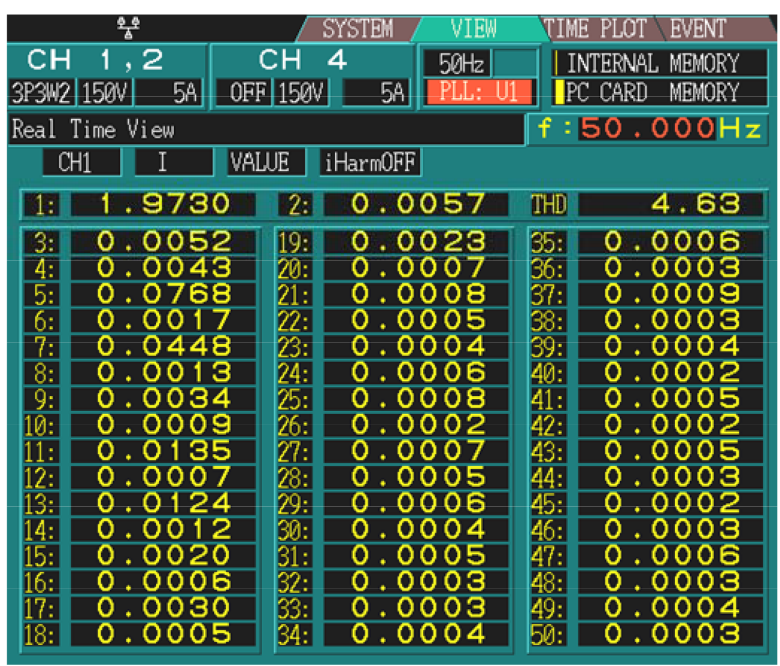

$c$

Fig. 14 Harmonic analysis of input phase current of the hybrid VIENNA rectifier

(a) Without, (b) With the proposed simplified algorithm of neutral-point control method, (c) With the neutral-point control based on a dual-carrier PWM method

this topology processes part of the output power $P_{\mathrm{o}}$. As mentioned in [1], the power allocation ratio between VIENNA rectifier and boost rectifier in this hybrid topology is $\sim 0.55: 0.45$. If the same output power is generated by the hybrid VIENNA rectifier and

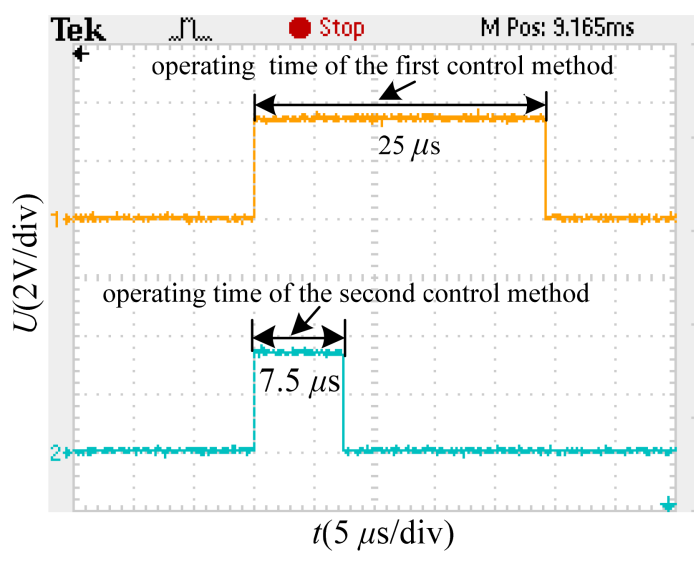

Fig. 15 Operating time of the two neutral-point control methods

Table 3 Comparison between the two neutral-point control methods

\begin{tabular}{|c|c|c|}
\hline \multirow[t]{2}{*}{ Performance } & \multicolumn{2}{|c|}{ Control method } \\
\hline & $\begin{array}{c}\text { Simplified } \\
\text { algorithm of } \\
\text { neutral-point } \\
\text { method }\end{array}$ & $\begin{array}{c}\text { Neutral-point } \\
\text { control based on } \\
\text { dual-carrier PWM } \\
\text { method }\end{array}$ \\
\hline neutral-point current $i_{0}$ & reduced & further reduced \\
\hline $\begin{array}{l}\text { three-time fundamental } \\
\text { frequency component }\end{array}$ & reduced & further reduced \\
\hline input current THD & reduced & further reduced \\
\hline $\begin{array}{l}\text { DC-link capacitor voltage } \\
\text { deviation }\end{array}$ & reduced & further reduced \\
\hline $\begin{array}{l}\text { computing resources of } \\
\text { control method }\end{array}$ & more & little \\
\hline
\end{tabular}

VIENNA rectifier, then just the power $0.45 P_{\mathrm{o}}$ is different, which is obtained by boost circuit in the hybrid rectifier while is also generated by VIENNA circuit in VIENNA rectifier, thus, the loss comparison between the hybrid VIENNA rectifier and VIENNA rectifier is equivalent to compare the loss for $0.45 P_{\mathrm{o}}$ obtained by boost rectifier (Fig. 16b) or VIENNA rectifier (Fig. 16c).

There are the same three-phase diode rectifier bridges with the same loss between boost rectifier as shown in Fig. $16 b$ and VIENNA rectifier as shown in Fig. 16c. The difference is the component quantity and its loss for switch, diode, and inductor during these two topologies. There are six switches in VIENNA rectifier but one switch in boost rectifier, thus, the switch loss in VIENNA rectifier is higher than the switch loss in boost rectifier for obtaining this $0.45 P_{\mathrm{o}}$, which enable the switch loss of VIENNA rectifier is higher than the switch loss of the hybrid VIENNA rectifier. The diode loss of VIENNA rectifier is higher because of including more diodes than boost rectifier; so, the VIENNA rectifier provides the higher diode loss compared with the hybrid VIENNA rectifier because this part of power $\left(0.45 P_{\mathrm{o}}\right)$ is processed by boost rectifier with less diode loss in the hybrid VIENNA rectifier. The VIENNA rectifier contains three boost inductors $\left(L_{a}\right.$, $\left.L_{b}, L_{c}\right)$; however, boost rectifier contains two boost inductors ( $L_{d 1}$, $\left.L_{d 2}\right)$. The inductors $\left(L_{d a}, L_{d b}, L_{d c}\right)$ of boost rectifier in AC-side are filter inductors for filtering the current surge spike with small inductance value, then, this inductor loss can be ignored because of a very small loss compared with boost inductor loss [1]; thus, boost rectifier because of including less boost inductors provides the lower inductor loss than VIENNA rectifier, which enable the hybrid VIENNA rectifier owns the lower inductor loss compared with VIENNA rectifier. Considering the loss of switch, diode, and Boost inductor, the hybrid VIENNA rectifier provides a lower total loss as well as own a higher efficiency compared with VIENNA rectifier because part of power is processed by boost rectifier with less loss in the hybrid VIENNA rectifier, this conclusion is also mentioned in [1]. 


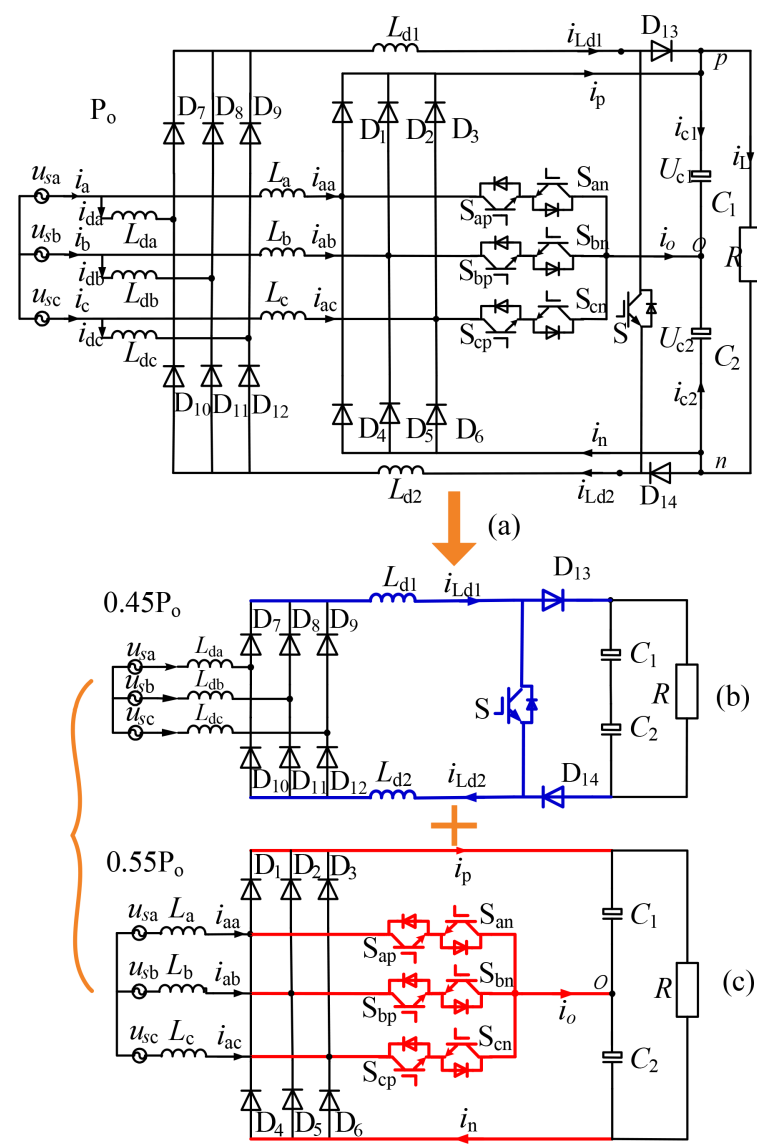

Fig. 16 Composite structure diagram for the hybrid VIENNA rectifier

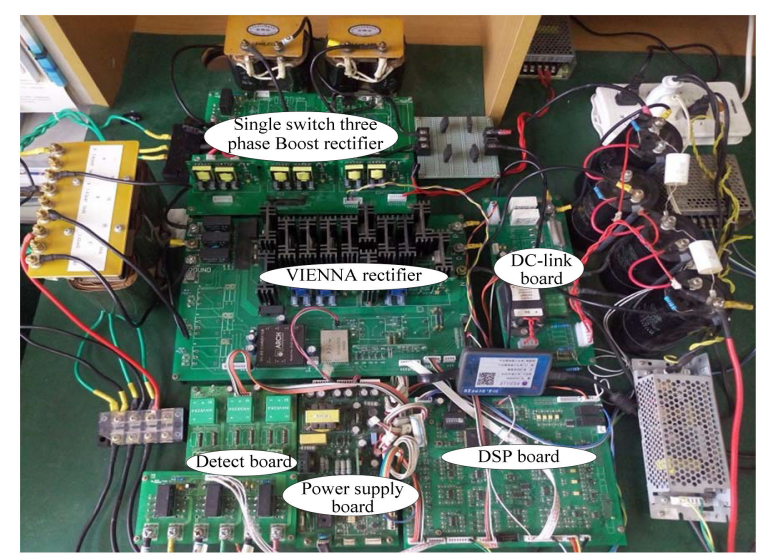

Fig. 17 Experimental prototype

\section{Results}

In order to verify the feasibility of the two control methods shown in Figs. 6 and 11, respectively, a power experiment platform was built controlling by a 32-bit DSP-type TMS320F2812, which is shown in Fig. 17, and the experimental parameters are shown in Table 4.

Figs. $18 a$ and $b$ show the input voltage, input phase current of the hybrid VIENNA rectifier $\left(i_{c}\right)$, input phase current of VIENNA (rectifier A) $\left(i_{a c}\right)$, input phase current of a single-switch threephase boost rectifier (rectifier B) $\left(i_{d c}\right)$, and the fundamental harmonic of input current $\left(i_{\mathrm{c}}\right)$ without the proposed neutral-point balancing control methods in a hybrid VIENNA rectifier. It can be seen that boost rectifier takes a part of the input current of this hybrid rectifier as well as reducing the current stress of the VIENNA rectifier. The THD of input current $\left(i_{c}\right)$ is $4.23 \%$, which is lower than $\mathrm{THD}=5 \%$, illustrating that the hybrid VIENNA rectifier has a good performance in low current THD and power factor (PF) under the $d-q$-axis cross-decoupling control system.
Table 4 Experimental parameters

\begin{tabular}{lc}
\hline grid voltage & $100 \mathrm{~V} / 50 \mathrm{~Hz}$ \\
DC-link voltage reference & $200 \mathrm{~V}$ \\
load resistor & $90 \Omega$ \\
AC-boost inductor $\left(L_{a}, L_{b}, L_{c}\right)$ of VIENNA & $10 \mathrm{mH}$ \\
DC-boost inductor $\left(L_{d 1}, L_{d 2}\right)$ of boost circuit & $2.5 \mathrm{mH}$ \\
AC-filter inductor $\left(L_{d a}, L_{d b}\right)$ of boost circuit & $0.07 \mathrm{mH}$ \\
DC-link filter capacitor & $3300 \mu \mathrm{F}$ \\
switching frequency & $10 \mathrm{kHz}$ \\
\hline
\end{tabular}
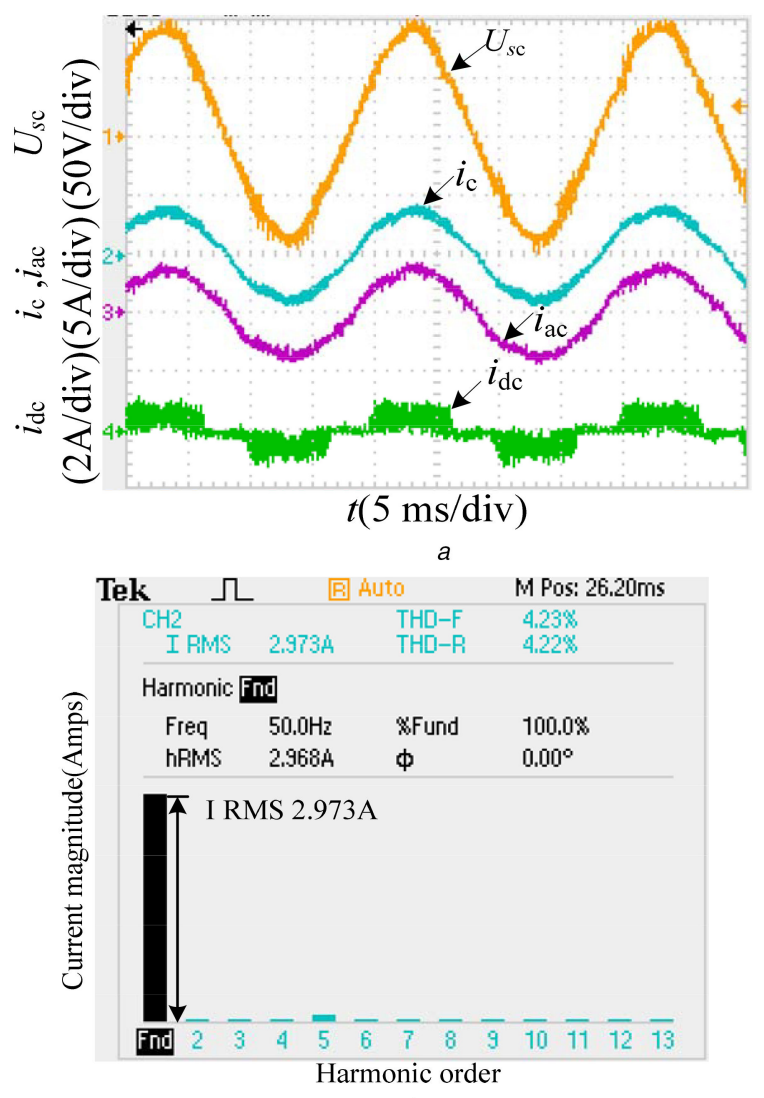

$b$

Fig. 18 Input voltage, input current, and harmonic order of the hybrid VIENNA rectifier without neutral-point control

(a) Input voltage and input current of the hybrid VIENNA rectifier, input current of VIENNA rectifier and boost rectifier, (b) Harmonic order of input phase current of the hybrid VIENNA rectifier

Fig. 19 shows the waveforms of input phase current $\left(i_{c}\right)$, the voltage of two DC-link capacitors $\left(U_{C 1}, U_{C 2}\right)$, and capacitors voltage deviation $\left(U_{C 1}-U_{C 2}\right)$ without and with the neutral-point control method. The DC-link voltage is measured with a DCcoupling channel. Fig. $19 a$ is the capacitors voltage deviation $\left(U_{C 1}-U_{C 2}\right)$ without the neutral-point control, and it can be seen that the voltage deviation $\left(U_{C 1}-U_{C 2}\right)$ is up to $5 \mathrm{~V}$. Fig. $19 \mathrm{~b}$ is the capacitors voltage deviation $\left(U_{C 1}-U_{C 2}\right)$ with the proposed simplified algorithm of neutral-point method, and it can be seen that the voltage deviation $\left(U_{C 1}-U_{C 2}\right)$ is reduced to $3.2 \mathrm{~V}$. Fig. $19 \mathrm{c}$ is the capacitors voltage deviation $\left(U_{C 1}-U_{C 2}\right)$ with the neutralpoint control based on a dual-carrier PWM method, and it can be seen that that voltage deviation $\left(U_{C 1}-U_{C 2}\right)$ is further reduced to $2.4 \mathrm{~V}$. Therefore, the neutral-point voltage fluctuation is effectively reduced in the two control method, which verifies the validity of the proposed scheme.

Fig. 20 shows the waveforms of input phase current $\left(i_{c}\right)$, the voltage of two DC-link capacitors $\left(U_{C 1}, U_{C 2}\right)$, and capacitors voltage deviation $\left(U_{C 1}-U_{C 2}\right)$ without and with the neutral-point control method. The DC-link voltage is measured with an AC- 


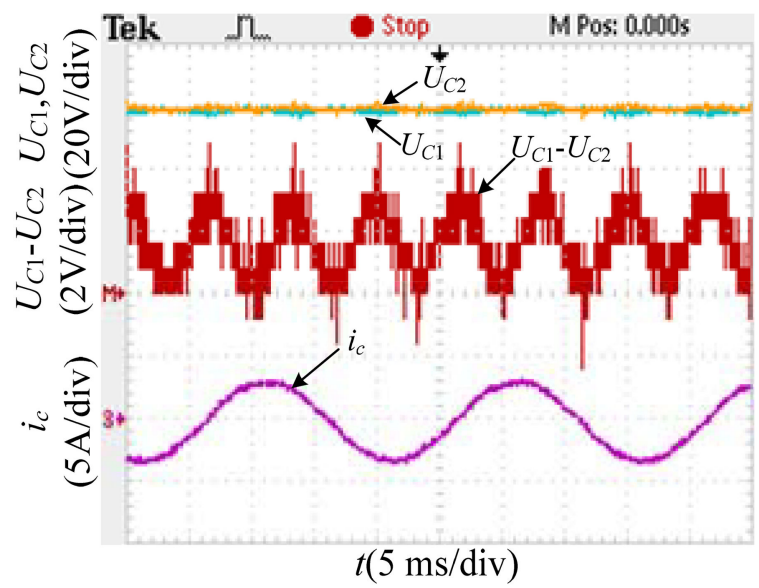

a
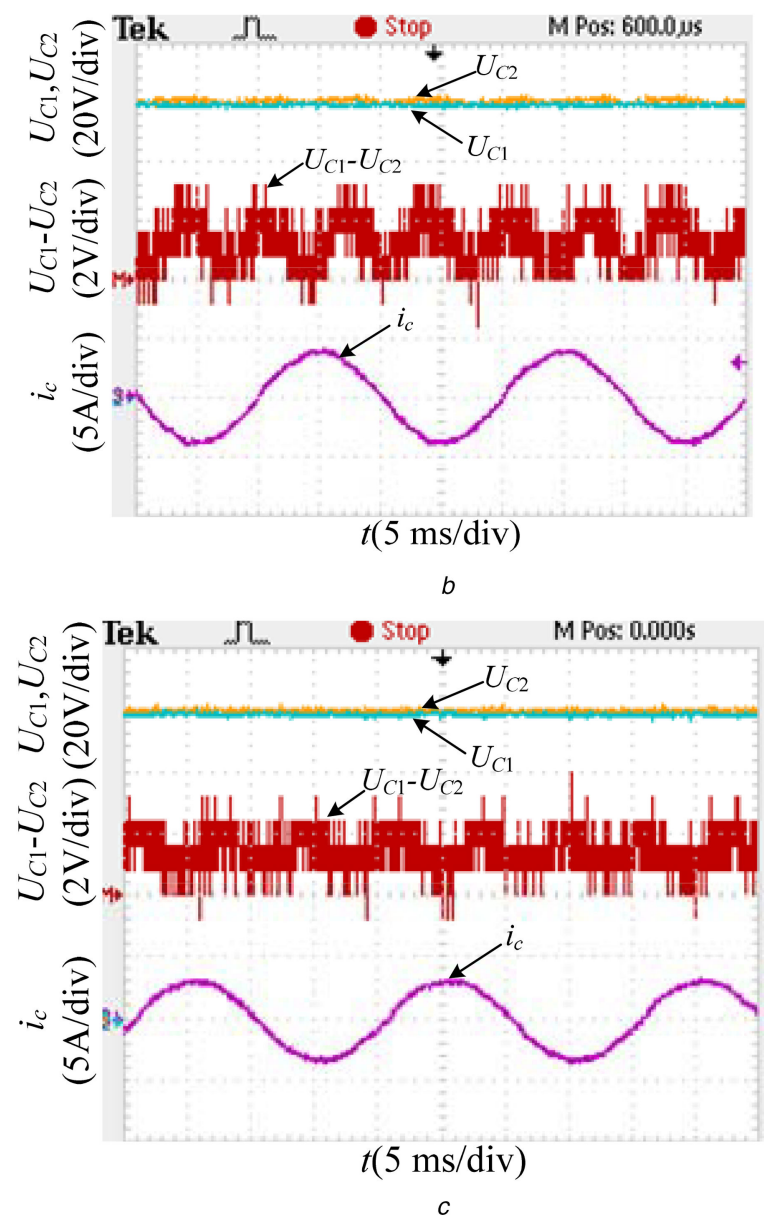

Fig. 19 Waveforms' comparison between

(a) Without the neutral-point control, (b) With the proposed simplified algorithm of neutral-point control method, (c) With the neutral-point control based on dual-carrier PWM method. (a) - (c) Scoping with a DC channel

coupling channel. Fig. $20 a$ is the capacitors voltage deviation $\left(U_{C 1}-U_{C 2}\right)$ without the neutral-point control, and it can be seen that the voltage deviation of two DC-link capacitors $\left(U_{C 1}-U_{C 2}\right)$ is up to $\pm 3 \mathrm{~V}$, which reflects the neutral-point current that presents a three-time fundamental. Fig. $20 b$ is the capacitors voltage deviation $\left(U_{C 1}-U_{C 2}\right)$ with the proposed simplified algorithm of neutral-point method, and it can be seen that the voltage deviation of three-time fundamental frequency component has decreased to $\pm 1.6 \mathrm{~V}$, which does effectively suppressed the capacitors voltage deviation when using the simplified algorithm of neutral-point method. Fig. $20 \mathrm{c}$ is the capacitors voltage deviation $\left(U_{C 1}-U_{C 2}\right)$ with the neutral-point control based on a dual-carrier PWM method, it can be seen that the voltage deviation of three-time fundamental frequency component fluctuations is up and down around zero, and it is
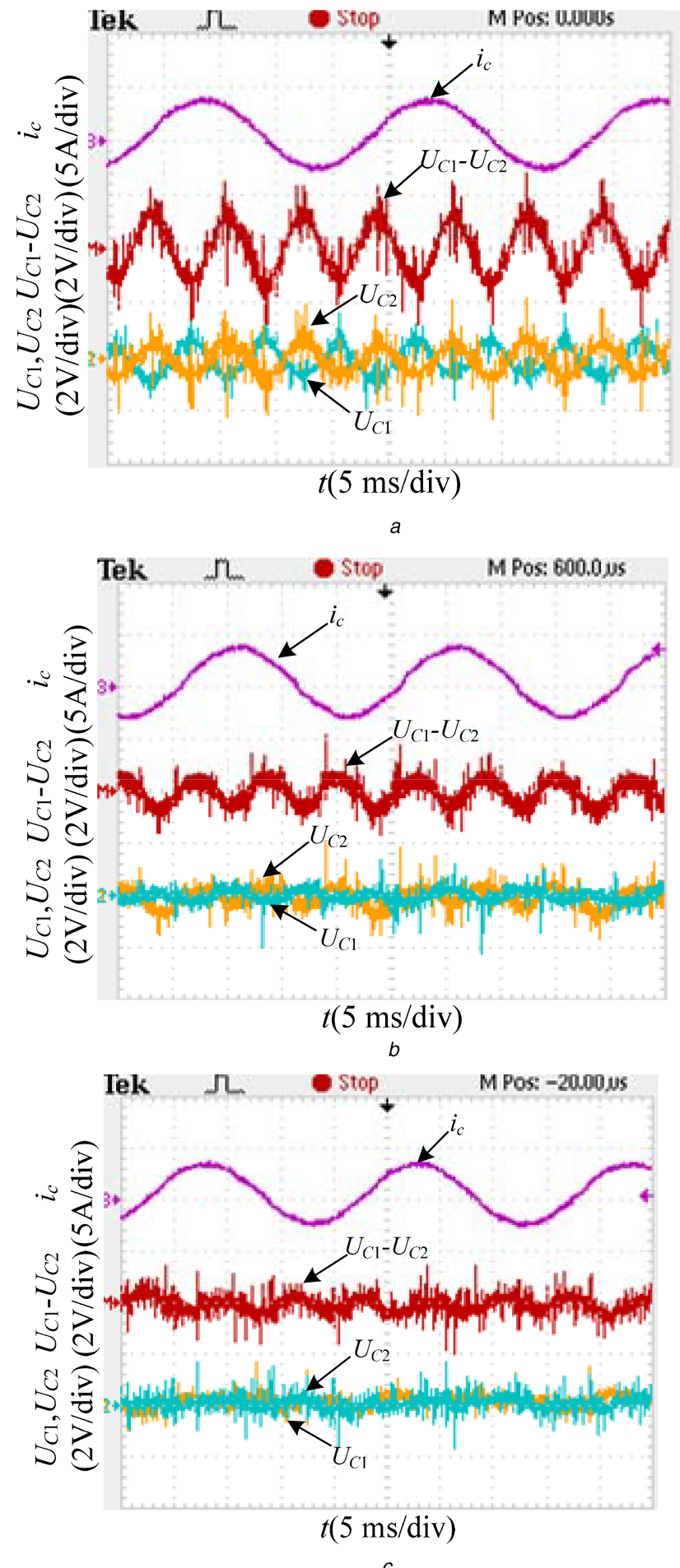

Fig. 20 Waveforms' comparison between

(a) Without the neutral-point control, (b) With the proposed simplified algorithm of neutral-point control method, (c) With the neutral-point control based on dual-carrier PWM method. (a)-(c) Scoping with an AC channel

measured within $\pm 1 \mathrm{~V}$, which verifies a better validity of the neutral-point control based on a dual-carrier PWM method.

Compared with Figs. 19 and 20, the changing trend of the DClink capacitors deviation measured with $\mathrm{DC}$ and $\mathrm{AC}$ channel can be seen in Fig. 13. From Fig. $13 a$, the voltage deviation $\left(U_{C 1}-U_{C 2}\right)$ has gradually decreased when using the proposed neutral-point control methods compared with that without the neutral-point control method. In Fig. 13b, the voltage deviation of the three-time fundamental frequency component of two capacitors has also gradually decreased when using the proposed neutral-point control methods compared with that without the neutral-point control method. Moreover, the neutral-point control based on a dual-carrier 


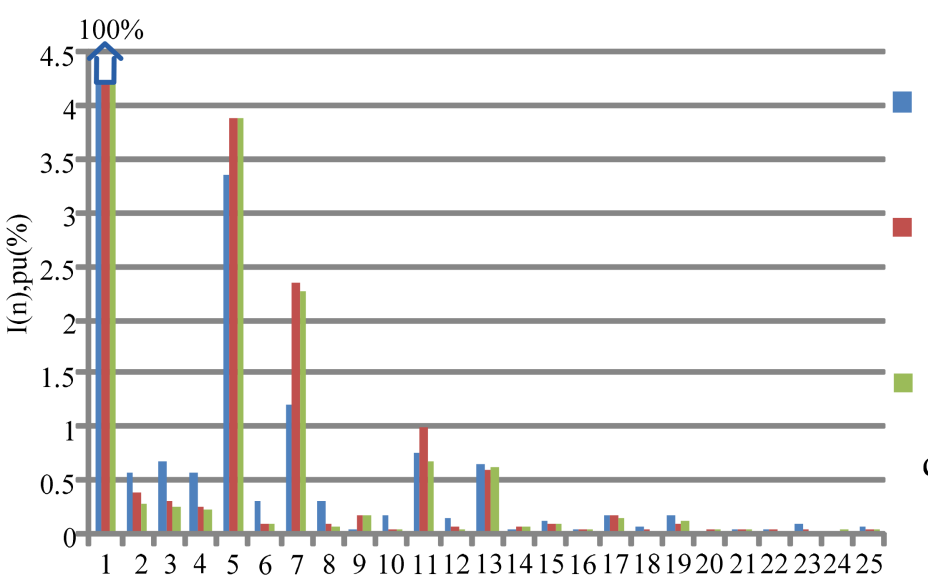

Without neutral-

point control

The simplified

algorithm neutralpoint control

The neutral-point control based on dual-carrier PWM method

Fig. 21 Per-unit value of low-frequency input phase current of the hybrid VIENNA rectifier harmonics

(a) Without neutral-point control method, (b) With the simplified algorithm of neutral-point control, (c) With the neutral-point control based on dual-carrier PWM method

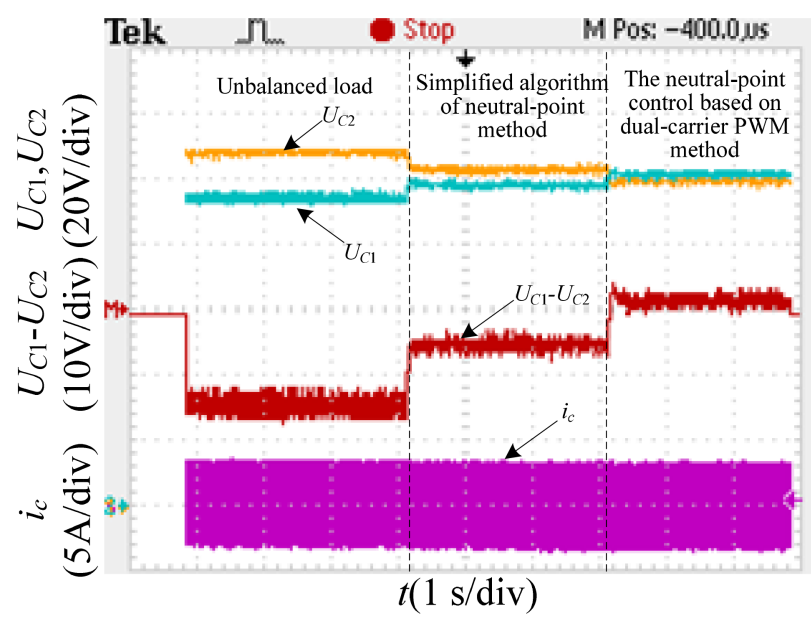

Fig. 22 Effect comparison between waves of different neutral-point balancing control method under unbalanced loads condition

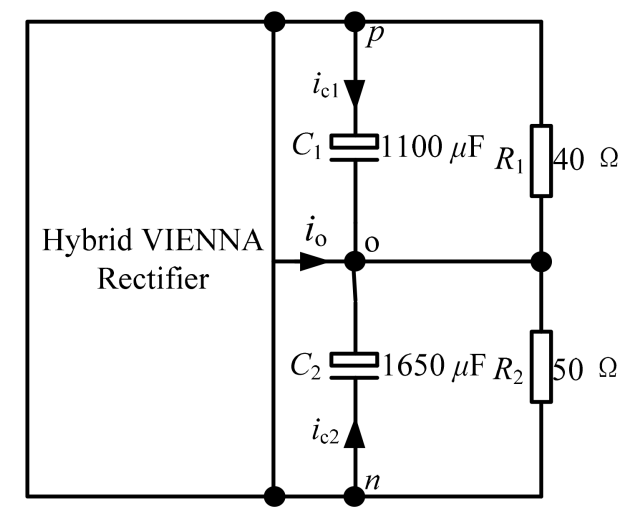

Fig. 23 Equivalent circuit of unbalanced load

PWM method is more effective for neutral-point fluctuation control than the simplified algorithm of neutral-point method.

Fig. 14 shows the harmonic magnitude of the input phase current without the neutral-point balancing control and that with the proposed two neutral-point control methods, which are obtained using a harmonic analyser. Fig. $14 a$ shows the input phase current THD without the neutral-point balancing control and it is $3.9 \%$. The second harmonic, the third harmonic, and the fourth harmonic of the input phase current are $0.0113,0.0135$, and 0.0111 , respectively. Fig. $14 b$ shows the input phase current THD under the proposed simplified algorithm of the neutral-point balancing control method and it is $4.67 \%$, which is higher than the THD without the neutral-point balancing control. However, this THD value is also lower than THD $=5 \%$ with the supply-side criterion. The second harmonic, the third harmonic, and the fourth harmonic of the input phase current are $0.0077,0.0063$, and 0.0052 , respectively. Fig. $14 c$ shows the input phase current THD under the neutral-point control based on dual-carrier PWM method and it is $4.63 \%$, which is higher than the THD without the neutral-point balancing control, but this THD value is also lower than THD $=5 \%$ with the supply-side criterion. The second harmonic, the third harmonic, and the fourth harmonic of the input phase current are $0.0057,0.0052$, and 0.0043 , respectively. Fig. 21 shows a harmonic comparison using a relative value with and without two proposed neutral-point balancing control methods. Comparing the second harmonic, the third harmonic, and the fourth harmonic in the three conditions, it can be seen that after adding two neutral-point balancing control methods, the THD of the input phase current has increased and THD value is also $<5 \%$, but the second, third, and fourth harmonics of the input phase current are decreased compared with those have not applied the neutral-point balancing control method. This shows that the two neutral-point balancing control methods have the ability to suppress the low-frequency input currents harmonics. Moreover, the neutral-point control based on dual-carrier PWM method has better effects on suppressing the low-frequency input currents harmonics than the simplified algorithm.

Fig. 22 shows the effect comparison between waves of different neutral-point control methods under the unbalanced loads conditions $\left(C_{1}: 1100 \mu \mathrm{F}, C_{2}: 1650 \mu \mathrm{F}, R_{1}: 40 \Omega, R_{2}: 50 \Omega\right)$. The equivalent circuit of the abnormal load condition is shown in Fig. 23. From waves, it can be seen that the voltage deviation $\left(U_{\mathrm{c} 1}-U_{\mathrm{c} 2}\right)$ is effectively suppressed when using the proposed two neutral-point balancing control methods compared with that without the neutral-point balancing control. Furthermore, by applying the simplified algorithm of neutral-point control method, the voltage deviation $\left(U_{c 1}-U_{c 2}\right)$ is further suppressed, and the neutral-point voltage fluctuation has been effectively reduced, which verifies the validity of the proposed simplified algorithm of neutral-point control method and can be applied in the abnormal operating condition such as unbalanced load.

\section{Conclusion}

This paper presents two control methods to solve the problem of the voltage deviation of DC-link capacitors in a hybrid rectifier composed of a three-level VIENNA rectifier and a three-phase single-switch boost-type rectifier. The voltage deviation of DC-link capacitors can be effectively reduced and the three-time fundamental frequency component of neutral-point current can be eliminated by using the two proposed control methods. Specifically, one neutral-point control algorithm based on zerosequence component injection simplifies the computing resource and has a good effect on controlling the voltage deviation. Another neutral-point control algorithm based on dual-carrier PWM method needs to divide the three-phase modulation signal into 12 sectors, and then calculates the corresponding modulation waveform in each sector to suppress the voltage deviation, and this method has a 
better controlling effect on suppressing the voltage deviation of DC-link capacitors even under the abnormal condition such as unbalanced loads. In addition, the hybrid VIENNA rectifier, after being introduced to the two methods, still exhibits a low input current THD. Moreover, these neutral-point methods are also very suitable for practical implementation. This hybrid rectifier in this paper is expected to be applied in a retrofit project as a frond-end AC/DC power supply of charging pile used for an electric vehicle where a three-phase diode rectifier already exists.

\section{Acknowledgments}

This project is supported by National Natural Science Foundation of China (51877176), Shaanxi international exchange and cooperation project (2017KW-035), Shaanxi Provincial Education Department of Service Local Special Plan Project (18JC024), State Key Laboratory of Large Electric Drive System (SKLLDJ022016008), and Research Funding for Xi'an University of Technology (2016CX034).

\section{References}

[1] Soeiro, T.B., Kolar, J.W.: 'Analysis of high-efficiency three-phase two- and three-level unidirectional hybrid rectifiers', IEEE Trans. Ind. Electron., 2013, 60, (9), pp. 3589-3610

[2] Costa, A.V., Rodrigues, D.B., Lima, G.B., et al.: 'New hybrid high-power rectifier with reduced THDI and voltage-sag ride-through capability using boost converter', IEEE Trans. Ind. Appl., 2013, 49, (6), pp. 2421-2436

[3] Wu, H., Zhan, X., Xing, Y.: 'Interleaved LLC resonant converter with hybrid rectifier and variable-frequency plus phase-shift control for wide output voltage range applications', IEEE Trans. Power. Appl., 2017, 32, (6), pp. $4246-4257$

[4] Lima, G.B., Finazzi, A.P., Freitas, L.C.., et al.: 'Single-phase high power factor hybrid rectifier suitable for high-power applications', IET Power Electron., 2012, 5, (7), pp. 1137-1146

[5] Thangavelu, T., Shanmugam, P., Raj, K.: 'Modelling and control of VIENNA rectifier a single phase approach', IET Power Electron., 2015, 8, (12), pp. 2471-2482

[6] Wang, Z., Cui, F, Zhang, G., et al: 'Novel carrier-based PWM strategy with zero-sequence voltage injected for three-level NPC inverter', IEEE J. Emerg. Sel. Topics Power Electron., 2016, 4, (4), pp. 1442-1451

[7] Kolar, J.W., Friedli, T.: 'The essence of three-phase PFC rectifier systems part I', IEEE Trans. Power. Electron., 2013, 28, (1), pp. 176-198

[8] Rodrigues, D.B. Costa, A.V., Lima, G.B., et al.: 'DSP-based implementation of control strategy for sinusoidal input line current imposition for a hybrid three-phase rectifier', IEEE Trans. Ind. Inf., 2013, 9, (4), pp. 1947-1963
[9] Izadinia, A.R., Karshenas, H.R.: 'Current shaping in a hybrid 12-pulse rectifier using Vienna rectifier', IEEE Trans. Ind. Electron., 2018, 33, (2), pp. $1135-1142$

[10] Long, B., Chu, S., Na, W., et al.: 'Study on power control of a novel hybrid rectifier applied to the aviation power source', (in Chinese), Proc. CSEE, 2016, 36, (4), pp. 1106-1116

[11] Song, W., Huang, J., Zhong, Y.: 'Hystersis current control method of VIENNA rectifier with midpoint potential balance control', (in Chinese), Power Syst. Technol., 2013, 37, (7), pp. 1909-1914

[12] Li, X., Sun, Y., Wang, H., et al:: 'A hybrid control scheme for three-phase Vienna rectifiers', IEEE Trans. Power Electron., 2018, 33, (1), pp. 629-640

[13] Adhikari, J., Prasanna, I.V., Panda, S.K.: 'Reduction of input curren harmonic distortions and balancing of output voltages of the Vienna rectifie under supply voltage disturbances', IEEE Trans. Power Electron., 2017, 32, (7), pp. 5802-5812

[14] Tian, K., Wu, B., Narimani, M., et al.: 'A capacitor voltage-balancing method for nested neutral point clamped (NNPC) inverter', IEEE Trans. Power Electron., 2016, 31, (3), pp. 2575-2583

[15] Xiang, C.Q., Shu, C., Han, D., et al.: 'Improved virtual space vector modulation for three-level neutral-point-clamped converter with feedback of neutral-point voltage', IEEE Trans. Power Electron., 2018, 33, (6), pp. 5452 5464

[16] Lee, J.S., Lee, K.B.: 'Performance analysis of carrier-based discontinuous PWM method for Vienna rectifiers with neutral-point voltage balance', IEEE Trans. Power Electron., 2016, 31, (6), pp. 4075-4084

[17] Song, W.Z., Xing, F.X., Yan, H., et al.: 'A hybrid control method to suppres the three-time fundamental frequency neutral-point voltage fluctuation in VIENNA rectifier', IEEE J. Emerg. Sel. Topics Power Electron., 2016, 4, (2), pp. $468-480$

[18] Alves, R.L., Font, C.H.I., Barbi, I.: 'A novel unidirectional hybrid three-phase rectifier system employing boost topology'. 2005 IEEE 36th Power Electronics Specialists Conf., Recife, Brazil, 2005, pp. 487-493

[19] Alves, R.L., Barbi, I.: 'Analysis and implementation of a hybrid high-powerfactor three-phase unidirectional rectifier', IEEE Trans. Power Electron., 2009, 24, (3), pp. 632-640

[20] Zhang, M., Hang, L., Yao, W et al. 'A novel strategy for three-phase/switch/ level (Vienna) rectifier under severe unbalanced grids', IEEE Trans. Ind. Electron., 2013, 60, (10), pp. 4243-4252

[21] Hang, L., Li, B., Zhang, M., et al.: 'Equivalence of SVM and carrier-based PWM in three-phase/wire/level Vienna rectifier and capability of unbalancedload control', IEEE Trans. Ind. Electron., 2014, 61, (1), pp. 20-28

[22] Zhao, W., Ruan, X., Yang, D., et al.: 'Neutral point voltage ripple suppression for three-phase four-wire inverter with independently-controlled neutra module', IEEE Trans. Ind. Electron., 2017, 64, (4), pp. 2608-2619

[23] Narendrababu, A., Agarwal, P. 'A hybrid modulation strategy for eliminating low frequency NP voltage oscillations in NPC using redistribution of NTV duty ratios', IET Power Electron., 2017, 10, (12), pp. 1504-1517

[24] Zhang, Y., Li, J., Li, X., et al.: 'A method for the suppression of fluctuations in the neutral-point potential of a three-level NPC inverter with a capacitorvoltage loop', IEEE Trans. Power Electron, 2017, 32, (1), pp. 825-836 